\title{
La justice administrative au brésil
}

\section{A justiça administrativa no brasil}

Ricardo Perlingeiro ${ }^{1}$

\section{RÉSUMÉ:}

Il s'agit d'une analyse descriptive de certains aspects du système de justice administrative brésilien, quant à la procédure administrative, au système judiciaire et à la procédure juridictionnelle, identifiant leurs aspects positifs et négatifs, de façon à servir de base à une étude comparée au regard des systèmes qui l'ont influencé, en Europe continentale et aux USA, et de ceux influencés par ces derniers en Ibéro-Amérique.

\section{MOTS-CLÉS:}

Procès équitable - Tribunal administratif - Droit compare.

\section{RESUMO:}

O texto contém uma análise descritiva de alguns aspectos do sistema de justiça administrativa brasileiro, quanto ao procedimento administrativo, sistema judiciário e processo judicial, identificando seus pontos positivos e negativos, de modo a servir de base para uma investigação comparada em face de sistemas que o influenciaram, na Europa continental e nos EUA, e daqueles que, por estes, foram igualmente influenciados no âmbito da Ibero-América.

\section{PALAVRAS-CHAVE:}

Processo justo - Tribunal administrativa - Direito comparado.

\footnotetext{
${ }^{1}$ Juge fédéral de Rio de Janeiro. Professeur à l'université Estácio de Sá et à l'université fédérale Fluminense.
} 


\section{INTRODUCTION}

Il convient d'amorcer un dialogue entre les systèmes brésilien et français en ce qui concerne le contentieux administratif. En effet, dans ce domaine, la production scientifique comparée entre le Brésil et la France est proportionnellement minime, bien que le modèle brésilien de "justice administrative", ait subi dans le passé l'influence de la France, avec son système dualiste de juridiction. En outre, même après que le modèle juridictionnel français ait succombé au Brésil, lors de l'instauration de la République, en 1891, remplacé par le modèle de juridiction unique, le droit administratif matériel français est encore une des sources d'inspiration de la doctrine et de la législation brésiliennes. ${ }^{2}$

À ce propos, la présente étude a pour but de procéder à une analyse descriptive et ponctuelle du système de justice administrative brésilien, en ce qui concerne la procédure administrative non contentieuse l'organisation et la procédure juridictionnelle, en en relevant certains aspects positifs et négatifs, à partir des principes d'État de Droit et de protection juridictionnelle effective, tels que concrétisés par les matrices du droit administratif en Europe $^{3}$ et de leur reflet dans certains modèles ibéro-américains, de façon à élaborer une étude comparée de ces systèmes avec le système français.

Dans un premier temps, il convient de déterminer la portée et le contexte de la terminologie utilisée. L'expression “contentieux administratif” se rapporte aux réclamations ou aux contestations d'un particulier vis à vis des actes d'une autorité administrative. L'expression “juridiction administrative” sert à désigner la prestation juridictionnelle destinée à la résolution d'un litige administratif, et “justice administrative”, désigne les organes de l'État responsables de rendre la justice. ${ }^{4}$

\section{RECOURS ADMINISTRATIF PRÉALABLE}

\footnotetext{
2 PERLINGEIRO, Ricardo; BLANKE, Hermann-Josef; SOMMERMANN, Karl-Peter (Coords.). Código de jurisdição administrativa: o modelo alemão. Rio de Janeiro: Renovar, 2009. p. 65.

$3 \mathrm{O}$ direito francês, o direito inglês e o direito alemão (FROMONT, Michel. Droit administratif des Etats européens. Paris: PUF, 2006. p. 7).

${ }^{4}$ UNIVERSITÉ FÉDÉRALE FLUMINENSE. Centre des Sciences du Pouvoir Judiciaire. Projeto Acadêmico do Programa de Pós-Graduação Justiça Administrativa - PPGJA-UFF. Niterói, 2008.
} 
En principe, dans un État de Droit, le contentieux administratif doit être confié exclusivement à une juridiction; cependant, il est admis que le conflit soit préalablement soumis à l'Administration Publique elle-même, sans que, néanmoins, cela constitue une exception au principe d'accès à la justice (subordination de l'Administration au juge). ${ }^{5}$ Nous faisons ici référence à la technique des autorités administratives supérieures auprès desquelles les intéressés, lorsqu'ils sont contrariés par l'Administration, interjettent un recours non contentieux devant l'autorité administrative hiérarchiquement supérieure, comme cela se trouve dans la plupart des systèmes, et de façon encore plus marquante en Allemagne, où les recours ont un effet suspensif automatique et constituent une condition sine qua non à l'introduction d'une action juridictionnelle. ${ }^{6} \mathrm{Je}$ me réfêre également à la technique des Autorités Administratives Indépendantes où les recours non contentieux sont jugés par des agents publics qui, en dépit du fait d'être nommés directement par des membres du premier échelon de l'Administration, exercent leurs fonctions de façon indépendante, n'étant pas subordonnés hiérarchiquement, à la différence des "tribunaux administratifs" anglais, des "commissions de recours" suisses et des "chambres administratives" en Autriche.

Au Brésil, ces deux techniques peuvent être observées et, respectant le principe de la protection juridictionnelle effective, elles constituent une possibilité pour les intéressés qui, même une fois exercée, n'exclut pas l'introduction simultanée d'actions visant à obtenir des mesures d'urgence. Le recours devant une autorité administrative supérieure, qui ne doit pas être confondu avec la réclamation préalable (très souvent indispensable à la constitution même du droit subjectif), est prévu dans la législation brésilienne de procédure administrative. ${ }^{8}$ Le recours devant une autorité administrative indépendante est semblable, par exemple, aux recours intentés devant le Conseil Administratif des Ressources Fiscales $(\mathrm{CARF}),{ }^{9}$ les agences régulatrices, ${ }^{10}$ les Tribunaux des Comptes ${ }^{11}$ et, pourquoi pas, devant le Conseil National de Justice (CNJ). ${ }^{12}$

\footnotetext{
${ }_{6}^{5}$ FROMONT, op. cit., p. 112-119.

${ }^{6}$ Verwaltungsgerichtsordnung/VwGO (Code de Juridiction Administrative - Loi du 21 janvier 1960), §§ 68, 80.

${ }^{7}$ FROMONT, op. cit.

${ }^{8}$ Loi n ${ }^{\circ} 9.784$, du 29 janvier 1999, art. $56 .$.

${ }^{9}$ Loi no 11.941 , du 27 mai 2009.

${ }^{10}$ Agence Nationale pour 1'Aviation Civile - ANAC (Loi $\mathrm{n}^{\circ}$ 11.182, du 27 septembre 2005); Agence Nationale des Eaux - ANA (Loi no 9.984, du 17 juillet 2000); Agence Nationale pour l'Énergie Électrique - ANEEL (Loi $\mathrm{n}^{\circ}$ 9.427, du 26 décembre 1996); Agence Nationale pour le Pétrole, le Gaz Naturel et les Bicombustibles - ANP (Loi ${ }^{\circ}$ 9.478, du 6 août 1997; Loi $n^{\circ}$ 9.990, du 21 juillet 2000; Loi $\mathrm{n}^{\circ}$ 12.351, du 22 décembre 2010); Agence Nationale pour la Santé Supplémentaire - ANS (Loi no 9.961, du 28 janvier 2000); Agence Nationale pour les Transports Terrestres - ANTT (Loi ${ }^{\circ} 10.233$, du 5 juin 2001); Agence Nationale pour la Vigilance Sanitaire ANVISA (Loi n ${ }^{\circ}$ 9.782, du 26 janvier 1999).
} 


\section{ORGANISATION DE LA JURIDICTION ADMINISTRATIVE}

La juridiction administrative proprement dite, substantiellement indépendante de l'Administration, fait l'objet d'une organisation que l'on peut classifier comme suit: (1) juridiction administrative ayant à la fois un rôle consultatif et un rôle contentieux, comme en France, ${ }^{13}$ aux Pays-Bas, ${ }^{14}$ en Italie, ${ }^{15}$ en Grèce, ${ }^{16}$ en Belgique ${ }^{17}$ et en Colombie, ${ }^{18}$ dont les Conseils d'État ont simultanément une fonction de cour suprême et d'organe consultatif; (2) juridiction administrative constituant un ordre juridictionnel autonome, avec une cour suprême de droit public spécifiquement, ayant un rôle uniquement contentieux, comme en Allemagne, ${ }^{19}$ en Autriche, ${ }^{20}$ en Suède ${ }^{21}$ et au Portugal; ${ }^{22}$ (3) juridiction administrative autonome de $1^{\circ}$ et $2^{\circ}$ degrés dépendante cependant d'une cour suprême unique, qui soit non seulement de droit public mais aussi de droit privé, comme en Espagne, ${ }^{23}$ en Suisse, ${ }^{24}$ en Hongrie $^{25}$ et au Mexique; ${ }^{26}$ (4) juridiction administrative "privée", connue également sous le nom de "juridiction unique" ou "système moniste", qui comprend droit public et droit privé, et qui est éventuellement dotée d'organes spécialisés en contentieux administratif, typique des

${ }^{11}$ Tribunal des Comptes de 1'Union - TCU (Loi nº 8.443, du 16 juillet 1992).

${ }^{12}$ Loi no 11.364 , du 26 octobre 2006.

${ }^{13}$ Code de Justice Administrative, R. 122-15, R. 122-18 e R. 122-20.

${ }^{14}$ Wet van 9 maart 1962, op de Raad van State (Loi du 9 mars 1962), art. $1^{\circ}$.

${ }^{15}$ Legge 27 aprile 1982, n. 186 (Loi no 186, du 27 avril 1982).

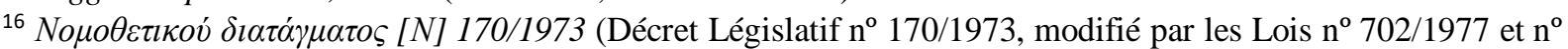
1.470/1984 et codifié par le Décret n $18 / 1989)$.

17 Constitution Belge (1993. Texte coordonné le 17 février 1994), art. 160; Loi du 23 décembre 1946 - Loi du Conseil d'État de Belgique (Loi du 23 décembre 1946).

${ }^{18}$ Constitución Política de Colombia (Constitution du 20 juillet 1991), art. 237; Ley nº 1.437, de 18 de enero de 2011.

${ }^{19}$ Verwaltungsgerichtsordnung/VwGO (Code de Juridiction Administrative - Loi du 21 janvier 1960), §§ 49 et 50 .

${ }^{20}$ Bundes-Verfassungsgesetz (Constitution du $1^{\circ}$ octobre 1920), art. 130, 1.

${ }^{21}$ Författning 1974 (Constitution de 1974. Approuvée le $1^{\circ}$ janvier 1975), art. $1^{\circ}$, Chapitre 11.

${ }^{22}$ Constitution de la République Portugaise, du 2 avril 1976, art. 209, 1, b; Code de Procédure des Tribunaux Administratifs (Loi no 4-A, du 19 février 2003).

${ }^{23}$ Constitución Española, de 29 de diciembre de 1978, art. 106, 1.

${ }^{24}$ Verfassung der Schweiz (Constitution approuvée par référendum le 12 mars 2000), art. 29 a, 191 et 191 b.

${ }^{25}$ Bírósági szervezet szóló 1997 (Loi de l’Organisation Judiciaire de 1997).

${ }^{26}$ Constitución Política de los Estados Unidos Mexicanos, de 5 de febrero de 1917, art. 94; Ley Orgánica del Tribunal Federal de Justicia Fiscal y Administrativa (Dernière réforme publiée le 3 juin 2011). 
systèmes de common law, comme en Angleterre, ${ }^{27}$ en Irlande, ${ }^{28}$ au Danemark, ${ }^{29}$ mais également présents en Argentine, ${ }^{30}$ au Chili, ${ }^{31}$ au Costa Rica, ${ }^{32}$ au Pérou ${ }^{33}$ et au Venezuela. ${ }^{34}$

Curieusement, le droit brésilien connaît les quatre modalités d'organisation de la juridiction administrative. Avant la République on se rapprochait de la juridiction administrative avec des fonctions à la fois consultative et contentieuse, malgré le fait que le Conseil d'État de l'Empire ait été calqué sur la première version du Conseil d'État français, avec une "justice retenue" entre les mains de l'Empereur, sans fonctions réellement juridictionnelles ou déléguées. ${ }^{35}$ Ce n'est qu'avec la Constitution de 1891 que le droit brésilien a connu la juridiction administrative, mais, à cette époque, elle possédait des caractéristiques propres aux systèmes du common law, avec des tribunaux amenés à connaître autant du droit public que du droit privé. Ce système de "juridiction unique" qui prédomine encore aujourd'hui, contient un certain niveau de spécialisation en droit public, ainsi qu'il en est question dans les "Varas de Fazenda Pública" (Chambres des finances publiques), de première instance, et dans les « sections » ou "Chambres" au niveau des cours d'appel. ${ }^{36}$ En ce qui concerne la Justice Fédérale de $1^{\circ}$ et $2^{\circ}$ Degrés, qui comprend une juridiction administrative compétente pour l'Administration Publique fédérale, ${ }^{37}$ il est permis de dire que ce modèle ressemble à l'espagnol et au suisse, en ce qu'elle est soumise à une même cour suprême, qui, connaît également du droit privé: le «Superior Tribunal de Justiça » (STJ Cour Suprême de Justice). ${ }^{38}$ En ce qui concerne la justice électorale, à l'inverse, le modèle est rigoureusement identique aux modèles allemand et portugais, avec une juridiction

27 ZILLER, Jacques. Administrations comparées. Les systèmes politico-administratifs de l'Europe des Douze. Paris: Montchrestien, 1993. p. 441.

${ }^{28}$ FROMONT, op. cit.

${ }^{29}$ ZILLER, op. cit.

${ }^{30}$ Constitución Nacional (Sancionada por el congreso general constituyente el $1^{\circ}$ de mayo de 1853 , reformada y concordada por la convención nacional ad hoc el 25 de septiembre de 1860 y con las reformas de las convenciones de 1866, 1898, 1957 y 1994), art. 116.

${ }^{31}$ Código Orgánico de Tribunales (Ley n 7.421 , de 15 de junio de 1943), art. $5^{\circ}, 2$.

${ }^{32}$ Constitución Política de la República de Costa Rica de 1949 (Actualizada hasta Ley n ${ }^{\circ} 8.365$, del 15 de julio del 2003), arts. 152 e 153; Ley Orgánica del Poder Judicial (Ley n 7.333/1993, modificada por la Ley $n^{\circ} 7.728$, de 15 de diciembre de 1997).

${ }^{33}$ Constitución Política del Perú de 1993, art. 139.

${ }^{34}$ Constitución de la República Bolivariana de Venezuela de 1999, art. 259.

${ }^{35}$ PERLINGEIRO; BLANKE; SOMMERMANN, op. cit., p. 65.

${ }^{36}$ Regimento Interno do Superior Tribunal de Justiça (Règlement Interne du Tribunal Supérieur de Justice), art. $9, \S 1^{\text {o }}$; Regimento Interno do Tribunal Regional Federal da $2^{\mathrm{a}}$ Região (Règlement Interne du Tribunal Régional Fédéral de la $2^{\mathrm{a}}$ Région), art. $2^{\circ}$, III, $\S 4^{\circ}$, et art. 13, III; Código de Organização e Divisão Judiciárias do Estado do Rio de Janeiro (Code de l'Organisation et de la Division Judiciaires de l'État de Rio de Janeiro), arts. 94, III, et 97 .

${ }^{37}$ Constitution de la République Fédérale du Brésil, du 5 octobre 1988, art. 109.

${ }^{38}$ Ibid., art. 105. 
administrative autonome et, au sommet, une cour suprême spécifique: le Tribunal Supérieur Electoral (TSE). ${ }^{39}$

\section{PORTÉE DE LA JURIDICTION ADMINISTRATIVE}

En ce qui concerne la portée de la justice administrative, dans un premier lieu, nous devons nous interroger à propos du rôle primordial de ses principes et de ses normes spécifiques. Pour quelle raison le législateur devrait-il traiter de façon différente l'organisation des tribunaux responsables de rendre la justice administrative? Pour quelle raison le législateur devrait-il disposer de façon spécifique en ce qui concerne la procédure juridictionnelle relative aux causes soumises à la justice administrative?

En effet, l'institution d'organes juridictionnels spécialisés compatibles avec une conception de justice de qualité et la consécration de principes et de règles spécifiques de justice administrative, qui considèrent, d'un côté, la fragilité du citoyen par rapport à l'Administration et, de l'autre, la pondération entre l'intérêt public et l'intérêt privé, sont des mesures dont l'objectif est d'assurer -en même temps- une protection juridictionnelle effective des droits du citoyen et du contrôle de la légalité de l'Administration Publique.

De ce fait, quelles sont, exactement, les exigences qui justifient l'existence d'une justice administrative?

En général, en ce qui concerne la définition de la compétence de la juridiction administrative, les systèmes d'Europe et d'Amérique Latine, appliquent les critères suivants: (1) celui des causes de droit administratif, où les conflits peuvent impliquer des autorités administratives ou des entités privées dans l'exercice de fonctions publiques, ainsi qu'il en est question en France, ${ }^{40}$ en Espagne, ${ }^{41}$ au Portugal, ${ }^{42}$ en Grèce, ${ }^{43}$ au Costa Rica, ${ }^{44}$ au Pérou, au Venezuela ${ }^{45}$ en Colombie ${ }^{46}$ et en Argentine; ${ }^{47}$ (2) celui des causes relatives aux actes ou actions administratives, excluant la responsabilité civile ou les contrats administratifs, comme

\footnotetext{
${ }^{39}$ Ibid., art. 118.

${ }^{40}$ Code de Justice Administrative, art. L. 211-1.

${ }^{41}$ Ley $n^{\circ} 23$, de 7 de julio de 1998 , art. $1^{\circ}, 1$.

42 Estatuto dos Tribunais Administrativos e Fiscais (Statut juridique des Tribunaux Administratifs et Fiscaux), (Loi $\mathrm{n}^{\circ} 13$, du 31 janvier 2002), art. $4^{\circ}$.

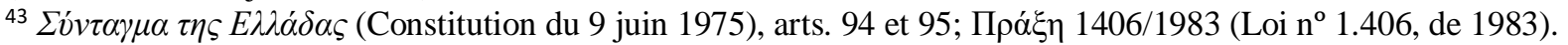

${ }^{44}$ Código Procesal Contencioso-Administrativo (Ley $\mathrm{n}^{\circ} 8.508$, de $1^{\circ}$ de enero de 2008), art. $1^{\circ}$.

${ }^{45}$ Constitución de la República Bolivariana de Venezuela de 1999, art. 259.

${ }^{46}$ Ley $n^{\circ} 1.437$, de 18 de enero de 2011, art. $2^{\circ}$.

${ }^{47}$ Ley Contencioso Administrativo de la Provincia de Buenos Aires (Ley n ${ }^{\circ} 12.008$, de $1^{\circ}$ de junio de 1999), art. $1^{\circ}$.
} 
en Allemagne, ${ }^{48}$ en Autriche ${ }^{49}$ et en Suisse $;^{50}$ (3) celui des causes circonscrites aux intérêts légitimes, sauf en ce qui concerne les droits subjectifs, comme en Italie ${ }^{51}$ et en Belgique; ${ }^{52}$ (4) celui des causes de droit public ou privé, dans la mesure où c'est dans l'intérêt de l'Administration, ceci étant typique des systèmes de juridiction moniste, comme en Angleterre, en Irlande, en Norvège, au Danemark, ${ }^{53}$ au Chili ${ }^{54}$ et au Mexique. ${ }^{55}$

Sur ce point également, le système brésilien apparaît hybride. En général, en cohérence avec son système moniste de juridiction, prévaut le critère de l'intérêt de l'Administration, indépendamment de la nature publique ou privée de la cause, à l'exemple de la compétence des Chambres des Finances Publiques et de la Justice Fédérale, et de l'application de normes procédurales spécifiques, comme c'est le cas du régime spécial pour l'exécution des jugements obtenus en défaveur de l'Administration (precatório judicial), ${ }^{56}$ ou de l'existence de délais allongés pour la défense de l'Administration. ${ }^{57}$

Cependant on trouve, enraciné dans le droit brésilien, lorsqu'il est question de la procédure juridictionnelle de référé "mandado de segurança", ${ }^{58}$ une situation analogue à celle du système allemand, où l'intéressé peut contester les actes administratifs, même s'ils émanent d'entités privées exerçant un pouvoir public, sans pour autant pouvoir prétendre, devant le même juge, à une quelconque indemnisation. Par ailleurs, le "mandado de segurança" brésilien mériterait un chapitre à part, considérant son évidente crise d'identité: premièrement, parce qu'il est inspiré des writs, aujourd'hui substitués par la claim for judicial review; ${ }^{59}$ deuxièmement, de par ses racines dans l'amparo mexicain (juicio de amparo), qui est clairement une procédure de juridiction constitutionnelle; troisièmement, à cause de ses évidentes caractéristiques du recours en excès de pouvoir français, de l'époque à laquelle cette

\footnotetext{
${ }^{48}$ Verwaltungsgerichtsordnung/VwGO (Código de Jurisdição Administrativa - Loi du 21 janvier 1960), § 40.

${ }^{49}$ FROMONT, op. cit., p. 147.

50 Bundesgerichtsgesetz, BGG (Loi du 17 juin 2005); Bundesgesetz über das Verwaltungsverfahren (Loi du 20 décembre 1968), art. $5^{\circ}$.

${ }^{51}$ Costituzione della Repubblica Italiana, de 27 de diciembre de 1947, art. 103.

52 FROMONT, op. cit., p. 150.

53 Ibid., p. 152-156.

${ }^{54}$ Código Orgánico de Tribunales (Ley no 7.421, de 15 de junio de 1943), art. 48.

${ }^{55}$ Ley Orgánica del Tribunal Federal de Justicia Fiscal y Administrativa (dernière réforme publiée le 3 juin 2011), art. 14.

${ }^{56}$ C'est-à dire injonction de payer obtenue en justice contre l'administration (ndt).

57 Constitution de la République Fédérale du Brésil, du 5 octobre 1988, arts. 100 et 109; Código de Processo Civil (Code de Procédure Civile), (Loi n ${ }^{\circ}$ 5.869, du 11 janvier 1973), arts. 191 e 730.

${ }^{58}$ Loi no 12.016, du 7 août 2009. (Procédure judiciaire spécifique permettant de contester des actes de l'Administration, $n d t$ ).

${ }^{59}$ FROMONT, op. cit., p. 191.
} 
mesure se limitait à l'annulation de l'acte administratif; ${ }^{60}$ finalement, parce qu'il se trouve actuellement inséré dans un système processuel et constitutionnel, au sein duquel, indépendamment de la procédure juridictionnelle choisie, l'intéressé peut formuler toute prétention à l'encontre l'Administration.

\section{JUGES RENDANT LA JUSTICE ADMINISTRATIVE}

Des prérogatives d'indépendance personnelle et institutionnelle doivent être assurées à la fois aux agents publics et à la structure juridictionnelle ayant pour mission de protéger les droits et les intérêts relevant de la juridiction administrative. Ainsi, les juges doivent être inamovibles et nommés à vie, et leur rémunération doit être juste et adéquate. La sélection, la carrière et la discipline des juges doivent être confiées à un organisme qui garantisse son indépendance, afin d'éviter une structure juridictionnelle verticale, marquée par le carriérisme et la subordination hiérarchique entre les juges. ${ }^{61}$ En outre, l'entrée dans la carrière de juge quel que soit le degré de juridiction - ne doit avoir lieu que par le biais d'un procédé ouvert, objectif et transparent, basé sur la qualification technique et la capacité professionnelle de l'intéressé.

Ces principes, contenus dans le Code Modèle de Procédures Administratives juridictionnelles et non contentieuses - pour l'Ibéro-Amérique, ${ }^{62}$ sont partiellement concrétisés par la Constitution brésilienne.

En ce qui concerne le droit brésilien, la nomination comme juge du premier degré est rendue possible à tout citoyen se soumettant à un concours public sur épreuves et sur titres. Les juges du premier degré parviennent au second degré par le biais d'une promotion, selon le critère du mérite ou de l'ancienneté alternativement, il est, en outre, exigé d'eux un perfectionnement constant auprès des écoles de Magistrature. Certains postes disponibles au second degré sont attribués selon un critère politique, suivant les propositions effectuées par des ordres professionnels (Ordre des Avocats du Brésil - OAB et Ministère Public), puis par les tribunaux, la nomination finale dépendant du chef de l'Exécutif. En ce qui concerne la Cour Suprême de Justice «Superior Tribunal de Justiça » le critère est similaire, bien

\footnotetext{
${ }^{60}$ Ibid., p. 164-168.

${ }^{61}$ ZAFFARONI, Eugenio Raúl. Poder Judiciário. São Paulo: Revista dos Tribunais, 1995.

${ }^{62}$ Código Modelo de Processos Administrativos - Judicial e Extrajudicial - para Ibero-América, arts. 26, 27, 28 et 29 (INSTITUT IBÉRO-AMERICAIN DE DROIT PROCESSUEL. Código Modelo de Processos Administrativos - Judicial e Extrajudicial - para Ibero-América. Buenos Aires: IIDP, 2012).
} 
qu'existe en outre la garantie de l'intervention du Parlement. ${ }^{63}$ Au Brésil, l'exercice de la juridiction administrative par un juge non professionnel n'est pas prévue, sauf en ce qui concerne les « juizados especiais ${ }^{64}$ mais bien que cette modalité bénéficie d'une autorisation constitutionnelle à l'art. 98, I et $\S 1^{\circ}$, elle n'a pas encore été transposée par une loi d'application.

La Constitution de 1988, à l'art. 96 II, a doté les Tribunaux d'un pouvoir d'autoorganisation consistant en l'élection de leurs organes directifs, en l'élaboration de leurs règlements internes, en l'organisation de leurs secrétariats, des services auxiliaires et en la nomination des juges qui leur sont rattachés, qu'il s'agisse de pourvoir des postes de magistrats de carrière de cette juridiction en question, ou de pourvoir des postes nécessaires à l'administration de la Justice. L'autonomie administrative et financière se matérialise, de même, par la concession aux tribunaux du pouvoir d'élaborer leurs propositions budgétaires dans les limites établies avec les autres Pouvoirs, conformément à la Loi des Directives Budgétaires.

Afin d'écarter la possibilité de dépendance externe, la Constitution à l'art. 95, établit, vis-à-vis des juges, des interdictions et des prérogatives, ${ }^{65}$ telles que: la nomination à vie, garantissant au juge la permanence dans ses fonctions jusqu'à l'âge de 70 ans, sauf en cas de condamnation définitive; l'inamovibilité, qui empêche que le juge puisse être transféré vers une autre juridiction, ce qui ne pourrait survenir que pour des motifs d'intérêt public et par décision du Tribunal à la majorité ou du Conseil National de Justice; et, finalement, l'irréductibilité de son salaire.

Cependant, l'effectivité de ces prérogatives institutionnelles et personnelles de la magistrature est remise en cause, comme, par exemple, en fonction de la nature du processus de constitution du budget, il est permis que le Pouvoir Exécutif puisse exercer une influence sur la concession de ressources au Judiciaire, permettant que le caractère irréductible de la rémunération soit à peine nominal, sans que le maintien de la valeur réelle ne soit assuré. D’un point de vue interne, malgré le fait que les juges se sentent pleinement indépendants, la

\footnotetext{
${ }^{63}$ Constitution de la République fédérale du Brésil, du 5 octobre 1988, art. 104.

${ }^{64}$ Juridiction des petites causes équivalent partiel des tribunaux d'instance (ndt).

65 Aux juges sont appliquées les interdictions suivantes: I - exercer, même en régime de disponibilité, à un autre poste ou fonction, n'étant celle de magistrat; II - la perception, à n'importe quel titre et sous aucun prétexte, de frais de justice ou de participation au procès, tout comme la réception d'aides ou de contributions de personnes physiques, entités publiques ou privées; III - la participation à des activités politiques ou reliées à des partis politiques ; IV - l'exercice de la fonction d'avocat au cours du jugement ou dans le tribunal duquel il s'est démis, avant que se soient écoulés trois ans de la démission du poste pour exonération ou retraite.
} 
solution selon laquelle les juges de $2^{\circ}$ degré puissent détenir un pouvoir disciplinaire et de sélection des juges du $1^{0}$ degré n'est pas idéale. ${ }^{66}$ Aux yeux de la société, cela peut donner l'impression d'une structure hiérarchique et carriériste, mettant en cause l'indépendance et l'impartialité, comme lorsque, par exemple, un juge de $1^{\circ}$ degré se prononçant à propos de la légalité des actes administratifs de la Cour ( $2^{\circ}$ degré) à laquelle il est rattaché ou encore des litiges intéressant ses membres.

\section{LA NÉCESSITÉ DE REPRÉSENTATION PAR AVOCAT DEVANT LA JURIDICTION ADMINISTRATIVE}

La présence de l'avocat, devant la justice administrative, doit être considérée comme un devoir, et non comme un droit, y compris en ce qui concerne l'Administration, qui a besoin de se faire représenter par un professionnel du Droit. Le caractère obligatoire de la présence d'un avocat devant la juridiction administrative est justifié par la complexité des litiges de droit public. De cette façon, s'agissant d'un devoir, l'État devra concéder le bénéfice de l'assistance juridique gratuite à ceux qui n'ont pas les moyens d'y subvenir. ${ }^{67}$

$\mathrm{Au}$ Brésil, malgré le fait que la présence de l'avocat ne soit facultative que devant les «Juizados Especiais », en réalité, l'intéressé a toujours à sa portée un conseiller juridique, même s'il s'agit d'un fonctionnaire du Judiciaire, et le système de gratuité de justice (avocat et frais) fonctionne de façon assez efficace et étendue au sein de la juridiction administrative. ${ }^{68}$

\section{LES PRÉTENTIONS RECEVABLES ET L'ÉTENDUE DU CONTRÔLE JURIDICTIONNEL}

S'agissant de son étendue, la compétence de la juridiction administrative doit être pleine, car elle doit être capable de réaliser intégralement le droit subjectif allégué et, doit donc, correspondre, si besoin, à une déclaration, annulation, injonction de faire, de ne pas faire, de donner ou de payer, y compris par le biais de mesures d'urgence ou d'exécution

\footnotetext{
${ }^{66}$ ZAFFARONI, , Eugenio Raúl. Poder Judiciário. São Paulo: Revista dos Tribunais, 1995.

${ }^{67}$ INSTITUT IBERO-AMÉRICAIN DE DROIT PROCESSUEL. Código Modelo de Processos Administrativos - Judicial e Extrajudicial - para Ibero-América, op. cit., arts. 32, 33 e 34.

${ }^{68}$ Constitution de la République Fédérale du Brésil, du 5 octobre 1988, art. $5^{\circ}$, LXXIV; Loi n ${ }^{\circ} 1.060$, du 5 février 1950.
} 
forcée. ${ }^{69}$ De cette plénitude de juridiction dépendent une protection juridictionnelle effective et l'État de Droit, dépassant ainsi le dogme selon lequel le juge ne peut imposer à l'Administration des obligations de faire, ni lui appliquer des amendes punitives ou coercitives (contempt of court civil et criminal), ni même exproprier ou mettre en gage des biens publics non essentiels. ${ }^{70}$ Le caractère effectif de la juridiction administrative n'est limité que par l'intérêt public, s'il est ponctuellement allégué et démontré, en observant les garanties d'une procédure légale, par le biais de mesures compensatoires en faveur de l'intéressé.

Le droit brésilien a beaucoup évolué à ce niveau-là. Le Code de Procédure Civile, applicable subsidiairement à la juridiction administrative, admet que toute sorte de prétention soit portée en justice à l'encontre de l'Administration. Des mesures d'urgence et d'exécution forcée sont prévues et il y a même la possibilité, en cas de stricte nécessité, d'obtenir le paiement d'une somme en espèces, conformément à la jurisprudence de la Cour Suprême Fédérale. ${ }^{71}$ Cependant, la difficulté majeure repose sur la pratique de l'Administration de remettre en cause les mesures d'exécution forcée sur la simple allégation d'atteinte à l'intérêt public, par le procédé de "suspension de mesure provisoire" ou de "suspension de l'exécution du jugement", ce qui ne s'encadre pas exactement avec le principe du contradictoire. ${ }^{72}$

L'exclusion de certains actes publics du contrôle juridictionnel continue à se vérifier dans la culture de certains systèmes, même si, sur le plan dogmatique, ne puisse plus être soutenue l'existence d'une catégorie spéciale d'actes qui, ontologiquement ne diffèrent d'ailleurs en rien des autres actes émis par l'Administration. ${ }^{73} \mathrm{Il}$ est indéniable que l'impossibilité de soumettre au contrôle juridictionnel le contenu politique d'actes publics n'est qu'un mythe. Cette question mérite d'être revisitée en partant des principes fondamentaux de juridiction administrative, en parallèle avec ceux de la juridiction constitutionnelle.

Au Brésil, le juge "bouche de la loi" est, en fait, une figure de rhétorique. ${ }^{74} \mathrm{La}$ réitération de la judiciarisation des politiques publiques de santé, affirmée par les différentes

\footnotetext{
${ }^{69}$ INSTITUT IBÉRO-AMÉRICAIN DE DROIT PROCESSUEL. Código Modelo de Processos Administrativos - Judicial e Extrajudicial - para Ibero-América, op. cit., Exposition de Motifs.

${ }^{70}$ Ibid., Exposition de Motifs.

${ }^{71}$ BRÉSIL. Cour Suprême Fédérale. AI 59.7182. 2 ${ }^{\mathrm{a}}$ Classe, Rapporteur min. Cezar Peluzo, DJ 6.11.2006.

${ }^{72}$ Loi no 8.437 , du 30 juin 1992, art. $4^{\circ}$.

${ }^{73}$ WOLFF, Hans J.; BACHOF, Otto; STOBER, Rolf. Direito administrativo.Traduction Antônio F. de Sousa. Lisbonne: Fondation Calouste Gulbenkian, 2006. p. 247; GARCÍA DE ENTERRÍA, Eduardo. La lucha contra las inmunidades del poder. 3. ed. Madri: Civitas, 1995. p. 70-78).

${ }^{74}$ SADEK, Maria Teresa. Judiciário e arena pública: um olhar a partir da ciência política. In: GRINOVER, Ada Pellegrini; WATANABE, Kazuo (Orgs.). O controle jurisdicional de políticas públicas. 1. ed. Rio de Janeiro: Forense, 2011. p. 1-33.
} 
sphères du Judiciaire brésilien, aux niveaux constitutionnel ou administratif, est un parfait exemple du fait qu'aucun acte émis par le pouvoir public ne peut être considéré à l'abri de la Justice. $^{75}$

Le contrôle juridictionnel des activités administratives doit englober, non seulement la forme et de contenu de l'acte administratif, mais aussi son caractère discrétionnaire s'il dépasse les limites autorisées par la loi, s'il dévie de sa finalité ou s'il porte atteinte aux droits ou principes fondamentaux, comme ceux de l'égalité, de la sécurité juridique, de la confiance légitime, de la proportionnalité et du raisonnable. ${ }^{76}$

Dans ce contexte, il est attendu de l'Administration un comportement au premier chef éthique et conforme à l'État de Droit, ayant comme principal objectif le respect des droits fondamentaux, et qu'elle agisse en obéissant aux principes du droit administratif, parmi lesquels je souligne les suivants.

\section{PRINCIPE DE LÉGALITÉ}

Le principe de légalité vise la soumission de l'Administration au droit, et le fait d'être prévu par les lois de procédure administrative tend à le renforcer, ainsi qu'il en est question dans la loi péruvienne de procédures administratives: "Las autoridades administrativas deben actuar con respeto a la Constitución, la ley y al derecho, dentro de las facultades que le estén atribuidas y de acuerdo con los fines para los que les fueron conferidas."77

En outre, il convient de relever que l'Administration doit veiller non seulement à la légalité ou à la constitutionnalité, mais aussi à la conventionnalité, et est ainsi autorisée à ne pas exécuter une loi ou une norme administrative à laquelle elle est soumise si elle la considère anticonventionnelle ou anticonstitutionnelle, tant que, sans préjudice du principe de subordination hiérarchique, elle en réfère aux organes de contrôle compétents afin que ceuxci en déclarent l'anticonventionnalité ou l'inconstitutionnalité. ${ }^{78}$ Cependant, entre nous, en

\footnotetext{
${ }^{75}$ BRÉSIL. Cour Suprême Fédérale, Plenum. SL 47 AgR. Rapporteur min. Gilmar Mendes, j. 17.3.2010, DJ 30.4.2010.

${ }^{76}$ INSTITUT IBÉRO-AMÉRICAIN DE DROIT PROCESSUEL. Código Modelo de Processos Administrativos

- Judicial e Extrajudicial - para Ibero-América, op. cit., art., art. 25.

${ }_{77}$ PÉROU. Ley del Procedimiento Administrativo General (Lei no 27.444, de 10 de abril de 2001), art. IV, 1.1.

${ }^{78}$ Henrique Savonitti Miranda met l'accent sur la controverse doctrinale au Brésil à propos de la possibilité que l'Administration refuse, simplement, d'exécuter des lois ou actes normatifs anticonstitutionnels. À faveur: Carlos Maximiliano; Francisco Campos; José Celso de Mello Filho; Caio Tácito; Manoel Gonçalves Ferreira Filho; Miguel Reale; Hely Lopes Meirelles. Contre: Celso Antônio Bandeira de Mello; Gilmar Ferreira Mendes;
} 
dépit de l'absence de prévision législative ou constitutionnelle expresse, s'impose à l'Administration l'initiative de rendre opérationnel de façon efficace ce procédé de rapport aux organes compétents, tant n'est pas justifiable son omission ou sa soumission, dans l'attente d'une intervention juridictionnelle, nationale ou internationale, à la loi anticonstitutionnelle ou anticonventionnelle.

À propos de l'absence d'une loi nationale relative au contrôle de la conventionalité, la Cour Interaméricaine des Droits Humains a décidé, litteris:

En relación con las prácticas judiciales, este Tribunal ha establecido en su jurisprudencia que es consciente de que los jueces y tribunales internos están sujetos al imperio de la ley y, por ello, están obligados a aplicar las disposiciones vigentes en el ordenamiento jurídico. Pero cuando un Estado ha ratificado un tratado internacional como la Convención Americana, sus jueces, como parte del aparato del Estado, también están sometidos a ella, lo que les obliga a velar porque los efectos de las disposiciones de la Convención no se vean mermados por la aplicación de leyes contrarias a su objeto y fin, que desde un inicio carecen de efectos jurídicos. En otras palabras, el Poder Judicial debe ejercer un "control de convencionalidad" ex officio entre las normas internas y la Convención Americana, evidentemente en el marco de sus respectivas competencias y de las regulaciones procesales correspondientes. En esta tarea, el Poder Judicial debe tener en cuenta no solamente el tratado, sino también la interpretación que del mismo ha hecho la Corte Interamericana, intérprete última de la Convención Americana. De tal manera, es necesario que las interpretaciones constitucionales y legislativas referidas a los criterios de competencia material y personal de la jurisdicción militar en México, se adecuen a los principios establecidos en la jurisprudencia de este Tribunal, los cuales han sido reiterados en el presente caso. Bajo ese entendido, este Tribunal considera que no es necesario ordenar la modificación del contenido normativo que regula el artículo 13 de la Constitución Política de los Estados Unidos Mexicanos. ${ }^{79}$

\section{PRINCIPES DE PROPORTIONNALITÉ ET PRINCIPE DU RAISONNABLE}

La doctrine brésilienne tend à établir une identité entre les principes du raisonnable et de proportionnalité. Selon Bandeira de Mello,

\footnotetext{
Zeno Veloso (MIRANDA, Henrique Savonitti. Licitações e contratos administrativos.Brasília: École Nationale de l'Administration Publique, 2004). Je pense, néanmoins, qu'il n'y a pas controverse concernant la possibilité de rapport quant à l'anti constitutionnalité auprès de l'organe compétent afin qu'il en soit fait état devant la Cour Suprême Fédérale.

${ }^{79}$ CORTE INTERAMERICANA DE DIREITOS HUMANOS. Caso Radilla Pacheco vs. México. Excepciones Preliminares, Fondo, Reparaciones y Costas. Sentencia de 23 de noviembre de 2009. Serie C No. 209.
} 
à proprement parler, le principe de proportionnalité n'est qu'une facette du principe du raisonnable. Il mérite une attention particulière, une référence spéciale, de façon à ce que l'on puisse mieux distinguer la physionomie d'un vice spécifique qui peut surgir et se montrer sous l'aspect d'un acte disproportionné, en soulignant, par conséquent, les possibilités de correction juridictionnelle ancrées dans ce fondement. Étant un aspect spécifique du principe du raisonnable, il est entendu que leur matrices constitutionnelles sont identiques. ${ }^{80}$

Bien que ces deux principes soient mentionnés à l'art. 2 de la loi $n^{\circ} 9.784 / 98$, seul celui de la proportionnalité y est explicité dans les termes suivants: «adéquation entre moyens et fins, est interdite l'imposition d'obligations, de restrictions et de sanctions supérieures en proportion à celles qui sont strictement nécessaires à l'observance de l'intérêt public » (art. 2, VI). Il convient de noter que, dans la législation, le principe ci-dessus, est lié à l'«intérêt public» et sera naturellement utilisé parallèlement aux principes d'égalité, de bonne foi et de protection de la confiance légitime, lors de l'exercice d'un pouvoir administratif discrétionnaire.

\section{PRINCIPE D'ÉGALITÉ}

Le pouvoir judiciaire doit être le destinataire du principe d'égalité, cherchant à traiter de la même façon les citoyens se trouvant dans la même situation de fait. A partir de cette idée est justifiée l'adoption de certains instruments procéduraux tels que: les actions collectives, les «súmulas vinculantes $»^{81}$ et le procès exemplaire, servant également l'idée d'un large accès à la justice et de la limitation des procédures juridictionnelles répétitives ou des causes de masse. Toutefois, s'agissant des causes de droit public, où est en jeu un comportement ou une action administrative de portée générale, l'égalité découlant de la prestation juridictionnelle est doublement nécessaire, principalement en raison du devoir d'égalité depuis toujours inhérent à l'administration publique, dans les sphères aussi bien matérielle qu'extrajuridictionnelle. ${ }^{82}$

\footnotetext{
${ }^{80}$ MELLO, Celso Antônio Bandeira de. Curso de direito administrativo.21. ed. São Paulo: Malheiros, 2006. p. 107-108.

${ }^{81}$ Arrêt de principe du STF à caractère contraignant (ndt).

${ }^{82}$ PERLINGEIRO, Ricardo. O princípio da isonomia na tutela judicial individual e coletiva, e em outros meios de solução de conflitos, junto ao SUS e aos planos privados de saúde. Dans: Noble, Milton; JOURS, Ricardo (s Org.). O Conselho Nacional de Justiça e os desafios da efetivação do direito à saúde. Belo Horizonte: Forum, 2011. p. 429-441
} 
Il ne serait pas logique qu'une action administrative originellement destinée à la communauté, une fois judiciarisée, ne soit opposable qu'à ceux étant disposés à l'introduire ; le pouvoir judiciaire ne pouvant être associé à une exégèse capable de rompre avec le principe d'égalité administrative. D'autre part, le principe d"égalité devant être observé par l'administration ne peut pas servir de justification à la négation de droits subjectifs. En effet, concéder à un citoyen un droit qui pourrait également être étendu à tous ceux se trouvant dans la même situation, mais sans l'étendre effectivement, fait imploser l'idée d'égalité. L'erreur, cependant, réside dans le fait que l'Administration n'étende pas ce bénéfice, et non dans le fait que le pouvoir Judiciaire ne reconnaisse pas ce droit. ${ }^{83}$

En effet, l'un des plus grands défis du droit administratif contemporain, est le manque d'uniformité des décisions administratives concernant les intéressés dans la même situation de fait, alimentant ainsi une pluralité de demandes répétitives, en particulier au niveau de la sphère juridictionnelle, mettant ainsi potentiellement en jeu la sécurité juridique. En Europe, dans certains systèmes nationaux, le principe d'égalité a du mal à être appliqué aux décisions administratives et la doctrine s'est peu dédiée aux recherches sur ce sujet. ${ }^{84}$

Selon le Code Modèle de Procédures Administratives pour l'Ibéro-Amérique, l'égalité de l'Administration doit être de telle sorte que, lorsque

La question de fond d'une prétention individuelle est rattachée aux effets juridiques d'un comportement administratif de portée générale, la solution du conflit doit devenir de l'intérêt de la collectivité destinataire de ce comportement et il en résulte que la solution ne saurait être trouvée qu'en une décision administrative unique, valant erga omnes. ${ }^{85}$

En conséquence directe, les accords judiciaires concernant des normes administratives ou des actions d'intérêt général administratif, atteindraient nécessairement tous ceux qui se trouveraient dans la même situation de fait, même s'ils n'ont pas participé à ces accords. ${ }^{86}$

\footnotetext{
${ }^{83}$ BRÉSIL. Tribunal Régional Fédéral de la $2^{\mathrm{a}}$ Region. AG 201102010109190. $5^{\mathrm{a}}$ Classe. Rapporteur juge Ricardo Perlingeiro, E-DJF2R 13.2.2012.

84 'L'existence du principe d'égalité dans le droit administratif ne fait l'objet d'aucune hésitation dans les divers pays étudiés. Certes le droit britannique a longtemps préféré parler de rationalité et de cohérence plutôt que d'égalité, même si les solutions concrètes étaient pratiquement les mêmes; mais depuis une vingtaine d'années, le principe d'égalité est ouvertement appliqué par le juge britannique." FROMONT, op. cit., p. 253-256.

${ }^{85}$ INSTITUT IBÉRO-AMÉRICAIN de DROIT PROCESSUEL. Código Modelo de Processos Administrativos Judicial e Extrajudicial - para Ibero-América, op. cit., art. $5^{\circ}$.

${ }^{86}$ Ibid., art. 72, II.
} 


\section{PRINCIPES DE SÉCURITÉ JURIDIQUE ET DE CONFIANCE LÉGITIME}

La sécurité juridique doit opérer de façon à limiter le pouvoir d'autocensure de ses propres actes par l'administration. L'annulation des actes, des normes ou des décisions administratives entachés d'illégalité, mais ayant apporté des bénéfices aux citoyens, dépend d'une procédure juridictionnelle préalable et doit survenir, d'un point de vue objectif, dans un délai déterminé, sauf s'il y a preuve de mauvaise foi, ou, selon un point de vue subjectif, lorsque n'est pas remise en cause la confiance de l'intéressé en la stabilité du comportement de l'Administration. ${ }^{87}$

Le principe de la confiance légitime, arrimé à une dimension subjective de la notion de bonne foi basée sur les droits fondamentaux, dérive des principes de la sécurité juridique et de l'État de Droit, il oriente la loi allemande, selon laquelle

un acte administratif invalide qui octroie ou est la condition d'une prestation pécuniaire immédiate ou échelonnée dans le temps, ne peut être invalidé si le bénéficiaire a cru dans la stabilité de l'acte administratif et si, sous réserve de l'intérêt public à le voir invalidé, cette confiance est digne de protection ; en règle générale on estime que la confiance est digne de protection si le bénéficiaire a disposé des prestations octroyées ou s'il a déjà conclu un contrat visant à en disposer, contrat qu'il ne peut plus annuler ou l'annulant à des conditions par trop préjudiciables pour lui. ${ }^{88}$

En dehors de ces cas, une fois abrogé l'acte invalide et pesé l'intérêt public, il faut déterminer la réparation à octroyer sur la base de la confiance en sa stabilité. ${ }^{89}$ Dans ces deux cas, la notion de confiance est écartée en présence de : dol, menace, corruption, connaissance de l'invalidité ou méconnaissance de celle-ci pour cause de faute grave de l'intéressé, obtention de l'acte à partir de données inexactes ou incomplètes..$^{90}$ Parallèlement, la validation putative, passé le délai d'un an à partir de la date de la prise de connaissance de l'invalidité, ne connaît d'exceptions qu'en cas de fraude, de menace et de corruption, étant ainsi écartés les autres aspects de la notion de confiance. ${ }^{91}$

Pour Forsthoff, dans le droit allemand, il n'existe que deux situations pour l'annulation des actes administratifs: abrogation (invalidation de l'acte n'ayant eu d'effet que

\footnotetext{
${ }^{87}$ Ibid., arts. 19 e 20.

${ }^{88}$ Verwaltungsverfahrensgesetz/VwVfG (Code Allemand de Procédures Administratives, du 25 mai 1976), § 48, numéro 2.

${ }^{89}$ Ibid., $\$ 48$, numéro 3.

${ }^{90}$ Ibid., $\$ 48$, numéro 2 , points 1,2 et 3 ; numéro 3 , deuxième phrase.

91 Ibid., $\$ 48$, numéro 4.
} 
sur le plan financier) et la révocation (invalidité d'un acte produisant des effets favorables). En principe, il n'est pas lieu à «libre» révocation, sauf si l'acte invalide est également antijuridique, comme dans les cas de dol ou lorsqu'il y a de nouvelles circonstances de fait et de droit. ${ }^{92}$

En droit administratif français, le principe de sécurité juridique est associé aux principes de non-rétroactivité et de respect des droits acquis (situations consolidées légalement). S'il y a modification d'une situation stabilisée, bien qu'illégale, l'Administration française concilie les principes de sécurité juridique avec l'“obligation de rétablir une situation conforme au droit" et, de ce fait, la décision administrative constitutive de «droits» contra legem peut être annulée, mais dans un certain délai. ${ }^{93}$ C'est la logique objective du droit français.

En droit britannique, la sécurité juridique est liée à la protection de la confiance légitime (legitimate expectations), de sorte que l'Administration ne doive pas induire l'intéressé en erreur, mais en ce qui concerne les situations consolidées illégalement, le droit anglais en arrive à être plus sévère que le droit français, en n'admettant jamais la possibilité de droits subjectifs contra legem. ${ }^{94}$ Toutefois, le droit administratif européen, qui exerce une influence croissante sur les systèmes nationaux européens, met l'accent sur le principe de la confiance légitime d'origine allemande. ${ }^{95}$

Partiellement en contradiction avec les termes de la súmula vinculante $e^{96}$ numéro 473 de la Cour Suprême Fédérale («L'Administration peut annuler ses propres actes lors qu'ils sont entachés de vices qui les rendent illégaux, car ils ne créent aucun droit...») la loi n9.784/99 a incorporé au droit brésilien le principe objectif français de sécurité juridique, parallèlement au subjectivisme allemand et à celui de confiance légitime, en particulier sur deux points: (1) déchéance du pouvoir d'annuler les actes administratifs ayant des effets favorables, au bout de cinq ans, sauf si la mauvaise foi est établie, (2) possibilité de validation putative des actes dont les défauts ne portent pas préjudice à l'intérêt public ou aux tiers.

L'absence de mauvaise foi - équivalant à l'absence de dol- associée à l'échéance du délai, justifient la validation d'actes ayant des effets favorables, bien que contraires à la loi et

\footnotetext{
${ }^{92}$ FORSTHOFF, Ernst. Tratado de derecho administrativo. Traduction Legaz Lacambra, Garrido Falla et Gómez de Ortega y Junge. Madrid: Instituto de Estudios Politicos, 1958. p. 359 et 363.

${ }^{93}$ FROMONT, Michel. Droit administratif des Etats européens. Paris: PUF, 2006. p. 261-269.

${ }^{94}$ Ibid., p. 268.

95 SIRINELLI, Jean. Les transformations du droit administratif par le droit de l'Union Européenne. Paris: LGDJ, 2011. p. 499.

${ }^{96}$ Précédent jurisprudentiel s'imposant aux juges (ndt). 
catalogués comme annulables (art. 54 de la Loi n 9.784/99: "L’Administration est déchue de son droit d'annuler les actes administratifs produisant des effets favorables au regard de ses destinataires à compter de cinq ans à partir de la date à laquelle ils ont été pratiqués, sauf si la mauvaise foi est établie”). La règle est analogue à celle que l'on trouve dans la VwVfG, $\S 48$, numéro 4.

Selon les dispositions de l'art. 55 de la loi n 9.784/99 («Les actes présentant des défauts réparables, pourront être validés putativement par l'Administration elle-même, dans une décision établissant clairement qu'ils ne portent atteinte ni à l'intérêt public ni aux droits des tiers.»), la validation putative en tout temps d'actes illégaux dépend de l'absence d'atteinte à l'intérêt public, qui, soulignons-le, ne peut être confondu avec les intérêts de l'Administration. Cependant, malgré cette lacune, la validation putative doit être limitée, uniquement lorsqu'elle est nécessaire à satisfaire les intérêts de ceux qui en bénéficient, en raison de la confiance manifestée à l'égard des Pouvoirs Publics et démontrée à chaque fois qu'il y aura de sérieuses raisons de croire en la stabilité de l'acte administratif. Cette règle passe alors pour avoir un lien direct avec le principe de la confiance légitime suivant l'exemple du $V w V f G, \S 48$, numéros 2 et 3 .

En ce qui concerne la protection des droits acquis comme condition à la révocation des actes administratifs, à l'art. 53 de la Loi $n^{\circ}$ 9.784/99, il semble clair que, dans des conditions normales, l'Administration ne révoque pas des actes licites constitutifs de droits légitimes. Par conséquent, la norme n'aurait de sens que si le terme "révocation" était appréhendé sous le point de vue allemand, quant à l'annulation des actes invalides ayant des effets favorables, et que les «droits acquis» dérivaient précisément de ces effets favorables. ${ }^{97}$ L'article ci-dessus pourrait également être interprété, comme dans la jurisprudence française, à partir de l'existence de deux catégories de décisions administratives, celles constitutives de droits (par exemple, celles conférant un avantage pécuniaire) et celles qui ne créent pas de droits (telles que celles résultant d'un pouvoir de police). Cependant, en ce qui concerne cette dernière uniquement, des faits postérieurs impactant ces droits pourraient conduire à l'annulation de l'acte. ${ }^{98}$

Dans ce contexte, je pense qu'au Brésil, est admissible l'exégèse selon laquelle, tant qu'il n'y a pas atteinte à l'intérêt public, les effets favorables et consommés des actes invalides doivent être préservés, de même que la réparation des dommages causés, en raison de la

\footnotetext{
${ }^{97}$ FORSTHOFF, op. cit., p. 359 e 363.

${ }^{98}$ FROMONT, op. cit., p. 266.
} 
confiance dont est dépositaire l'Administration. En l'absence de dol et passé un délai de cinq ans, en plus de préserver les effets consommés, l'acte administratif illégal est validé putativement.

\section{PRINCIPES DU PROCÈS ÉQUITABLE (DROITS DE LA DÉFENSE ET CONTRADICTOIRE)}

La procédure administrative doit être préalable afin de rendre légitime l'élaboration soulignons-le - de tous les actes administratifs individuels ayant des effets ponctuels et restrictifs de droits ou d'intérêts. Il est important de souligner que la possibilité d'un recours administratif contradictoire a posteriori, contestant l'acte administratif, n'exclut pas l'obligation d'une procédure préalable à la réalisation de ce même acte; la procédure administrative étant l'un des éléments constitutifs de l'acte administratif.

À ce sujet, les principes du contradictoire et de l'exercice des droits de la défense inhérents à la procédure administrative doivent respecter non seulement le droit d'être entendu - d'avoir son day in court - ou de produire des preuves, mais surtout celui d'obtenir une décision publique motivée, basée sur les arguments de fait et de droit produits par les parties. ${ }^{99}$ C'est la tendance de la jurisprudence de la Cour Suprême Fédérale, qui sous l'influence de la jurisprudence du Bundesverfassungsgericht, considère que le droit à la défense et au contradictoire impliquent non seulement le droit de se manifester et d'être informé, mais également le droit de l'individu de voir ses arguments pris en compte par l'organe juridictionnel. ${ }^{100}$

Mais ce qui semble évident, constitue encore aujourd'hui un défi au regard des résistances de l'Administration Publique brésilienne. Prenons l'exemple de deux cas paradigmatiques que l'on retrouve fréquemment dans les tribunaux, l'un concernant les actes administratifs individuels, l'autre les actes relatifs administratifs généraux.

\subsection{La retenue sur salaire des fonctionnaires publics}

\footnotetext{
99 INSTITUT IBÉRO-AMERICAIN DE DROIT PROCESSUEL. Código Modelo de Processos Administrativos - Judicial e Extrajudicial - para Ibero-América, op. cit, Exposition de Motifs.

100 BRÉSIL. Cour Suprême Fédérale. MS 25.787-3/DF. Rapporteur min. Gilmar Mendes. Brasília, DF.
} 
Le premier exemple concerne la retenue sur salaire des fonctionnaires publics, ayant pour but la restitution des sommes indûment versées, permise par la Loi $\mathrm{n}^{\circ} 8.112 / 29^{101}$, sans qu'ils ne puissent pour autant bénéficier d'une procédure administrative préalable.

L'idée selon laquelle l'Administration Publique détient, pour le recouvrement de dettes, le pouvoir de procéder à des retenues sur la rémunération de ses propres fonctionnaires, sans que ne soient observées les garanties d'un procès équitable, ainsi que des affirmations du type "le fonctionnaire public ne dispose d'aucun droit acquis à un régime statutaire"102, peuvent être associées aux vestiges d'une conception de la fin du XIXe siècle, les nommées «relations spéciales de pouvoir», selon lesquelles les fonctionnaires, pour satisfaire les prétentions découlant de leur lien de subordination à l'Etat, étaient toujours soumis à des statuts ou à des normes spéciales auxquelles ne pouvaient s'appliquer les droits fondamentaux, le principe de légalité ou de sécurité juridique. ${ }^{103}$

Ces relations spéciales de droit public, institutionnalisées constitutionnellement, se caractérisaient par un ordre disciplinaire statutaire propre, avec une force obligatoire uniquement interne ${ }^{104}$, fondées et limitées tant par l'application de la loi, comme, par exemple, dans les relations découlant du service militaire obligatoire, que par la volonté de l'intéressé lui-même, tel que dans les relations avec les fonctionnaires publics ou les militaires de carrière.

À l'époque, on en venait à dire que l'enseignant pouvait, "sans détours, détenir et emprisonner l'étudiant négligent», ${ }^{105}$ le citoyen quittait la société et entrait dans l'organisation institutionnelle de l'État. ${ }^{106}$ Cette vision, à l'époque liée à un État de Droit purement formel, est aujourd'hui dépassée. En Allemagne, la rupture définitive avec l'exégèse selon laquelle les relations spéciales de pouvoir créaient des espaces juridiquement vides a eu lieu à partir de la décision de la Cour Constitutionnelle Fédérale, qui, en date du 14 mars 1972, a affirmé que

${ }^{101}$ Loi $\mathrm{n}^{\circ}$ 8.112, du 11 novembre 1990 (Rédaction élaborée à partir de la Mesure Provisoire $\mathrm{n}^{\circ} 2.225-45$, du 4.9.2001), art. 46.

102 BRÉSIL. Cour Suprême Fédérale. AI 64.1911, $A g R .1^{a}$ Classe. Rapporteur min. Carmen Lúcia, j. 8.9.2009, DJe 1.10.2009; BRASIL. Cour Suprême Fédérale. RE 116.683. Rapporteur min. Celso de Mello, DJ 13.3.1993; BRÉSIL. Cour Suprême Fédérale. AI 685-866-AgR. Rapporteur min. Ricardo Lewandowski, DJe 22.5.2009.

${ }^{103}$ MAURER, Hartmut. Direito administrativo geral. Barueri: Manole, 2006. p. 195.

${ }^{104}$ MAYER, Otto. Derecho administrativo alemán. Buenos Aires: Depalma, 1982. t. I, § 10, III, p. 170-171. FORSTHOFF, op. cit., p. 201.

${ }^{105}$ W. Jellinek, VerwR S. 122, S. 341, apud MAURER, op. cit., p. 195.

${ }^{106}$ WOLFF; BACHOF; STOBER, Direito administrativo. Traduction Antônio F. de Sousa. Lisboa: Fundação Calouste Gulbenkian, 2006..p. 111. 
les droits fondamentaux peuvent également être invoqués pour la mise en œuvre de sanctions administratives. ${ }^{107}$

Il est clair que les prétentions d'un fonctionnaire se rapportant exclusivement à ses attributions administratives, ne sont qu'apparentes et les conflits éventuels doivent être résolus interna corporis par l'Administration elle-même, n'existant pas, dans ces cas, un droit subjectif proprement dit. L'Administration n'a pas de droits à l'égard d'elle-même, tel était le sens de l'institut de la « relation spéciale de pouvoir », associé à un cadre interne, et partant, juridiquement vide.

D'où, la juste affirmation selon laquelle le Pouvoir Judiciaire ne doit pas connaitre des questions interna corporis de l'Administration; elle doit respecter les statuts, règles et règlements, qui, par exemple, établissent les critères de choix interne d'un dirigeant d'une université publique (autonomie universitaire) ou encore d'un tribunal, puisque les effets d'un conflit de cette nature s'épuisent internement et qu'il n'y a pas, en toute logique, de droits subjectifs à protéger juridictionnellement. Il en va de même en ce qui concerne la structure administrative du Pouvoir Législatif (élection à des commissions parlementaires, etc.).

Toutefois, si un fonctionnaire allègue une atteinte à sa sphère patrimoniale, la prétention correspondante, même si elle provient directement de son lien à l'administration, devra être considérée sous couvert des droits fondamentaux. A la différence de ce qui s'est déjà dit par le passé, le fonctionnaire public n'est plus l'objet d'un « pouvoir spécial », mais il demeure un sujet de droit. ${ }^{108}$

\subsection{Les droits de la défense dans les décisions du TCU}

La deuxième situation concerne la procédure administrative préalable comme condition des décisions rendues par la Cour des Comptes.

Pendant de nombreuses années, au Brésil a prévalu l'idée selon laquelle, au cours d'une procédure administrative devant la Cour des Comptes, la garantie du droit à la défense aux éventuels intéressés n'était pas nécessaire. Ceci car cette procédure s'entendait comme exclusivement retournée contre l'Administration, constituant, ainsi, une procédure interne de contrôle de la légalité de l'Administration. Le cas échéant, les intéressés devraient faire valoir directement leurs droits auprès de l'administration. Cependant, en réalité,

\footnotetext{
${ }^{107}$ BverfGE, 33, 1.

${ }^{108}$ WOLFF; BACHOF; STOBER, op. cit., p. 494.
}

Revista Juris Poiesis - Rio de Janeiro. Vol.22-n²8, 2019, pg.157-189. ISSN 2448-0517

Rio de Janeiro, 29 de abril de 2019. 
l'Administration, orientée par le principe de la subordination hiérarchique, ne serait en aucun cas en mesure de contrarier la position prise par la Cour des Comptes, rendant ainsi le droit à la défense purement protocolaire, sans aucun effet pratique.

En 2007, la Cour Suprême Fédérale a publié la « súmula vinculante » numéro 3, en ces termes: "Au cours des procédures portées devant la Cour des Comptes de l'Union, sont assurés le contradictoire et les droits de la défense lorsqu'il peut résulter de la décision l'annulation ou la révocation d'un acte administratif dont bénéficie l'intéressé [...]". ${ }^{109}$ Toutefois, la Cour des Comptes, lors de l'interprétation de cet arrêt, a décidé que

Il n'appartient pas au TCU d'instaurer une procédure contradictoire à tous ceux que concernent les décisions génériques du Tribunal - prises dans l'exercice de sa compétence constitutionnelle d'exiger des personnes soumises à sa juridiction la parfaite application de la loi - c'est-à-dire de contenu uniquement objectif, sans tenir compte des situations concrètes et subjectives, donc sans la présence du sujet passif déterminé. ${ }^{110}$

Ainsi que nous l'avons mentionné plus haut, toute procédure administrative doit assurer le respect des droits de la défense et du principe du contradictoire, dans le but de légitimer la prise d'actes ayant une répercussion envers les intéressés. Cependant, de fait, en raison de l'essence même de la procédure administrative, seuls les actes et les décisions administratives individuels permettent l'exercice préalable du droit à la défense. Il faut reconnaître que, lorsque l'on parle de la constitution d'actes généraux, concrets ou abstraits, ou d'actes individuels quant à leurs effets généraux, la procédure administrative prévoit le mécanisme du contradictoire différé ou reporté. Dans ces cas-là, en raison de l'impossibilité de convoquer chaque individu impliqué afin de défendre ses intérêts, cette diligence est remplacée par une consultation publique ou une audience publique, prévues par la législation brésilienne aux arts. 31 et 32 de la Loi $n^{\circ} 9.784 / 1999$, ce procédé comporte une correspondance dans les ordres juridiques d'autres pays d'Amérique Latine, comme le Costa Rica, le Pérou, le Mexique et le Venezuela. ${ }^{111}$

${ }^{109}$ BRÉSIL. Cour Suprême Fédérale. Súmula Vinculante $n^{\circ}$ 3. Session Plenière, 30 mai 2007. Brésilia, DF, DJe $\mathrm{n}^{\circ} 31$ de 6.6.2007, p. 1 .

110 BRASIL. Tribunal des Comptes de l'Union. Acórdão (Arrêt) 2.553/2009. Session Plénière. Rapporteur min. José Jorge, DJ 4.11.2009.

111 BREWER-CARÍAS, Allan. Principios del procedimiento administrativo en América Latina. Bogotá: Legis, 2003. p. 98-99. En France, la participation des intéressés au processus de prise de décisions d'intérêt collectif constitue un débat difficile, elle est prise en charge par la Commission Nationale de Débat Public, ayant aujourd'hui un statut d'autorité administrative indépendante et elle a la fonction d'assurer le renforcement de la participation populaire dans le processus d'élaboration de projets urbains ayant un impact économique et 
En outre, il convient de souligner que sera ultérieurement garantie à l'intéressé la faculté d'amorcer une nouvelle procédure administrative disposant d'une totale possibilité de défense de façon à écarter les effets individuels de l'acte général provenant de la procédure administrative antérieure, au cours de laquelle il a été représenté par les entités qui ont pu participer aux audiences et aux consultations publiques.

Rappelons, enfin, que les questions d'intérêt général ne peuvent être décidées par une autorité administrative de degré inférieur à celle qui a donné lieu au conflit. La compétence incombera à l'autorité qui détient le pouvoir d'autocensure s'agissant de la question de fond soulevée par les intéressés. Ainsi, dans le cas où la prétention implique la déclaration d'invalidité ou d'illégalité d'un acte administratif, seule l'autorité administrative compétente pour annuler un acte ou son supérieur pourra juger la procédure, sous peine d'irrespect ou d'insubordination administrative.

Par conséquent, les Tribunaux des Comptes doivent toujours s'abstenir de déléguer à l'Administration la garantie des droits de la défense et du principe du contradictoire, et doivent commencer à recevoir, eux-mêmes, les procédures administratives visant à la contestation individuelle de leurs décisions où la question de fond est d'intérêt général, afin d'assurer le respect des garanties d'un procès équitable. Il convient en outre de souligner que les effets favorables de la solution finale sont nécessairement étendus à tous ceux se trouvant dans la même situation de fait. ${ }^{112}$

\section{LA RÉALITÉ DE L’ADMINISTRATION BRÉSILIENNE}

Je considère que, d'une manière générale, la justice administrative brésilienne, sa structure organique, ses juges, ses normes et ses principes procéduraux, sont en accord avec les principes fondamentaux de la protection juridictionnelle effective et de l'État de droit.

environnemental. (POCHARD, Marcel. La Administración Pública y la protección de los derechos fundamentales. In: CONSEJO DE ESTADO DE LA REPÚBLICA DE COLOMBIA. Seminario FrancoColombiano sobre la Reforma a la Jurisdicción Contencioso Administrativa. Bogotá: Imprenta Nacional de Colombia, 2008. p. 85-86; FROMONT, op. cit., p. 220-221). La loi britannique est celle qui a le plus investi dans les procédures publiques, par le biais d'audiences publiques: "Incontestablement, c'est le droit britannique qui a donné le plus d'importance aux procédures publiques qui sont appelées enquêtes publiques. Ce qui caractérise les enquêtes, c'est que celles-ci commencent par des mesures de publicité permettant à l'ensemble des personnes intéressées de prendre part aux audiences qui sont ensuite organisées de façon contradictoire, selon un modèle quasi juridictionnel, mais qui ne portent en principe que sur la situation de fait du territoire concerné, ce qui permet ensuite à l'autorité administrative compétente de prendre en considération des objectifs qui dépassent le strict cadre territorial" (FROMONT, op. cit., p. 220).

112 À l'exemple du Règlement Intérieur du Tribunal des Comptes (Approuvé par la Résolution administrative $\mathrm{n}^{\circ} 15$, en date du 15 Juin, 1993), aux arts. 161 et 281. 
Cette évaluation peut aussi s'appliquer à la législation brésilienne concernant la procédure administrative.

Cependant, il est possible d'avoir la sensation que, dans la société brésilienne, les droits subjectifs ne sont pas respectés par l'Administration, ${ }^{113}$ et que le Pouvoir Judiciaire est lent et incapable de répondre à la hauteur de ce qui est attendu de lui. ${ }^{114}$ En réalité, les données statistiques indiquent l'existence d'un nombre croissant de conflits impliquant l'Administration $^{115}$ et, proportionnellement, une augmentation de la durée de conclusion des procès ${ }^{116}$ bien que, paradoxalement, les structures juridictionnelles ne cessent de croître, et

113 Comme il en ressort de l'étude réalisée par le CNJ Justiça em números, les causes découlant d'une relation juridique de droit public, ayant comme demandeur ou défendeur les Pouvoirs Publics, représentent une majorité absolue des cas portés devant les tribunaux. "Justiça em números" est un système, comme indiqué sur le site du CNJ <http://www.cnj.jus.br/>, qui vise l'élargissement du processus de connaissance du Pouvoir Judiciaire par le biais du prélèvement et de la systématisation de données statistiques et du calcul des indicateurs statistiques décrivant la performance des tribunaux. Dans le cas précis de cette étude, il est important de connaître le profil des demandes et de chercher à déterminer la participation du gouvernement dans les actions en justice, le contentieux et la quantité de travail, considérant la quantité de nouveaux cas, l'accumulation de travail du magistrat, le taux de congestionnement de la justice, la quantité de recours externes et internes et le taux de réformation des décisions. Selon les données recueillies par le CNJ pour l'année de référence 2009, les Pouvoirs Publics ont porté devant la Justice Fédérale de 1er degré, un total de 3.458.831 (trois millions quatre-cent cinquante huit mille huit-cent trente et un) de nouveaux cas. Dans cet ensemble, sont inclus les cinq tribunaux régionaux et les actions en justice de l'Union, des municipalités, des fondations et des entreprises publiques fédérales, des États, du District fédéral, des municipalités, des fondations et des États et des districts des entreprises publiques de l'État et des districts, des communes, des municipalités, des fondations et des entreprises publiques municipales. Un total de 2.580.232 (deux millions, cinq-cent quatre-vingt mille deux-cent trente deux) actions ont été portées devant la justice de $1^{\circ}$ degré à l'encontre des Pouvoirs Publics. En ce qui concerne les actions en justice de 2ème degré, les Pouvoirs Publics ont porté en justice un total de 740818 actions (sept-cent quarante mille huit-cent dix-huit) a contrario 676966 (six-cent soixante-seize mille neuf-cent soixante six) ont été portées contre lui. Devant les tribunaux des Etats fédérés, les Pouvoirs Publics, en tant que demandeurs, ont atteint un total de 4.126.159 (quatre millions cent vingt-six mille cent cinquante neuf) actions, en précisant que, comme indiqué sur le site, certains Etats de la Fédération ne disposant pas de toutes les données, il peut être conclu que le résultat réel est plus élevé que celui susmentionné. Dans ce nombre, sont compris les deux degrés de juridiction. Devant les tribunaux des États fédérés ce sont 1.134.963 (un million cent trente quatre mille neufcent soixante trois) demandes au total ont été déposées contre les Pouvoirs Publics en 2009.

114 MATSUURA, Lilian. Para brasileiro, Justiça é lenta, cara e parcial. Consultor Jurídico, 22 fev. 2009.

${ }^{115}$ Cette affirmation peut être démontrée par une étude menée par le Département de Recherches Judiciaires du Conseil National de la Justice ayant pour but d'identifier ceux qui avaient intenté le plus d'actions en justice (les 100 premiers) auprès des tribunaux des Etats fédérés, des tribunaux régionaux fédéraux et des tribunaux du travail. Il a été démontré que l'Institut National de Sécurité Sociale (INSS) est l'objet de plus d'un cinquième des actions en justice du classement total. Le secteur Public Fédéral est en tête en ce qui concerne le nombre de litiges, avec un total de 38,5\%, suivi par le Secteur Public des Etats fédérés, avec un pourcentage de 7,8\%, et un total de 5,2\% pour le Secteur Municipal, soit un total 51,5\% pour les entités de l'Administration Publique. Cela signifie que l'Union, les États, les Communes, les organismes municipaux et les fondations, soit au total environ 20 entités, (trois) personnes juridiques de droit public et 15 personnes juridiques de l'administration indirecte, atteignent un plus grand nombre de demandes que les 80 premiers plaideurs du pays, figurant parmi eux l'ensemble des secteurs de la banque et des télécommunications. Données disponibles sur le site: <http://www.cnj.br/iagens/pesquisa-judiciarias/pesquisas_litigantes-pdf>. Consulté le: 3 Juin 2011 (Moraes, Vânila Cardoso de. Demandas repetitivas decorrentes de ações ou omissões da Administração Pública: hipóteses de soluções e a necessidade de um direito processual público fundamentado na Constituição. la .En 2011. 231 f. Mémoire (Master en Justice Administrative) - Université Fédérale Fluminense, Niterói, RJ, 2011). 116 «(...) la 2ème instance de la Justice Fédérale, en particulier le TRF (Tribunal Régional Fédéral) de la 1ère Région, n'est pas en mesure, malgré la mise en oeuvre des processus d'amélioration de la gestion des procédures, 
qu'il en est de même des dépenses. ${ }^{117}$ C'est le symptôme qui indique que quelque chose ne fonctionne pas bien.

En effet, il y a un écart ou un décalage temporel entre la législation et la réalité de l'Administration Publique brésilienne.

J'ai essayé de démontrer que la plupart des conflits dérivent, parfois par méconnaissance, d'une résistance de l'Administration à se conformer aux principes fondamentaux énoncés dans les normes de procédure administrative, qui constituent l'épine dorsale du droit administratif. Au Brésil, encore aujourd'hui, 15 ans après la publication de la Loi Générale de Procédure Administrative (Loi n ${ }^{\circ}$ 9.784) et 25 ans après la promulgation de la Constitution, nous vivons avec une Administration qui date de l'époque où les actes administratifs étaient pris sans permettre l'exercice préalable des droits de la défense ou du contradictoire. Le manque généralisé d'anticipation des fonctionnaires publics a pu être notoirement constaté au moment de l'entrée en vigueur de la nouvelle loi relative à l'accès aux informations. Les journaux, y compris les publications du gouvernement, informaient alors de la surprise des fonctionnaires publics “qu'est-ce que c'est que cette loi d'accès aux informations?"118

\section{CONSIDÉRATIONS FINALES}

de raccourcir les délais de jugement. Au contraire, ces délais s'étendent, résulte de ce constat la preuve irréfutable de la stabilité ou même de l'augmentation au fil des ans, du congestionnement de l'appareil judiciaire, comme indiqué ci-dessous:

\begin{tabular}{|l|l|}
\hline TRIBUNAL & 2004 \\
\hline TRF (moyenne) & $67,1 \%$ \\
\hline TRF de la 1ère Région fédérale & $69 \%$ \\
\hline
\end{tabular}

Données obtenues à partir du site Web du CNJ et constant dans Cartilha Novos Tribunais: uma questão de Justiça, organisé par l'Association des Juges Fédéraux de Minas Gerais (AJUFEMG), Novembre 2010.(ASSOCIATION DES JUGES FÉDÉRAUX de MINAS GERAIS - AJUFEMG (Brésil).Cartilha Novos Tribunais: uma questão de justiça. Minas Gerais: AJUFEMG, 2010. p. 34). Taux de congestionnement: nombre de procédures qui sont entrées dans le système et qui n'ont pas été jugées <http://www.cnj.jus.br/>. Notez qu'une grande partie de cette augmentation se doit au changement de la méthodologie adoptée par le CNJ, entre les années 2008 et 2009, s'agissant du calcul du taux de congestionnement » (Moraes, op. cit.).

117 Depuis 1989, la Justice Fédérale de 1ère instance a augmenté 470\%, étant présente dans plus de 214 municipalités. Grâce à la loi n ${ }^{\circ} 12.011 / 2009$, plus de 230 chambres fédérales ont été créées et leur installation se concluera entre 2010 à 2014, élevant cette croissance à un taux de $606 \%$ et à 273 municipalités. (ASSOCIATION DES JUGES FÉDÉRAUX DE MINAS - AJUFEMG (Brésil). Cartilha Novos Tribunais: uma questão de justiça, op. cit.).

${ }^{118}$ BRUNO, Cássio; BASTOS, Isabela; CASTRO, Juliana; RAMALHO, Sérgio. Que lei de acesso é essa?, reage uma servidora. O Globo, le 17 mai 2012. 
Dans ce contexte d'adversités, de culture et de mentalité issues du passé, je trouverais précipité voire même téméraire, dans un premier temps, d'accroître le pouvoir de l'Administration en matière de résolution des contentieux administratifs, en restreignant ou en admettant l'accès à la Justice à titre seulement subsidiaire. Mais je reconnais qu'à moyen terme, le perfectionnement des «autorités administratives indépendantes » est la voie naturelle.

Toutefois, nous avons besoin d'une réforme, cependant elle ne porterait à ce stade sur le Pouvoir Judiciaire ou la législation processuelle administrative (juridictionnelle et non contentieuse), mais sur la propre Administration; une réforme urgente qui concernerait notamment la qualification et la formation des agents publics, sur les aspects techniques et éthiques, permettant de lutter contre la corruption et qui conduise à une Administration efficace, crédible et renforcée telle un véritable troisième pouvoir. Nous avons besoin d'une réforme qui conduise à une Administration qui ne se cacherait pas derrière l'application stricte du principe de légalité, délégant par commodité au Pouvoir Judiciaire la reconnaissance de droits trouvant leur source dans la Constitution et dans les Conventions Internationales des Droits de l'Homme. Et finalement, nous avons besoin d'une réforme qui conduise à une Administration engagée en faveur de l'Etat de Droit, qui sans s'appuyer sur le Pouvoir Judiciaire, dispose de l'initiative d'assurer les droits fondamentaux.

\section{RÉFÉRENCES}

ALLEMAGNE. Bundesverfassungsgerichts (BverfGE). BVerfGE 33, 1. Entscheidungen des Bundesverfassungsgerichts (BverfGE). Disponible sur le site: $<$ http://sorminiserv.unibe.ch:8080/tools/ainfo.exe?Command=ShowPrintVersion\&Name=bv0 33001>. Consulté le: 16 juil. 2012.

. Verwaltungsgerichtsordnung ( $V w G O)$. Code de Juridiction Administrative. Loi du 21 janvier 1960 (BGBl. I S. 17), modifiée et nouvellement promulguée le 19 mars 1991 (BGB1. I S. 686), actualisée selon les altérations imposées par l'article 3 de la Loi du 21 décembre 2006 (BGBl. I S. 3316) et par l'article 13 de la Loi du 12 décembre 2007 (BGB1. I S. 2840). Disponible sur le site: <http://www.gesetze-im-internet.de/bundesrecht/vwgo/gesamt.pdf>. Consulté le: 12 juil. 2012.

. Verwaltungsverfahrensgesetz $(V w V f G)$. Code allemand de procédures administratives du 25 mai 1976. Disponible sur le site: <http://www.gesetze-im-internet.de/vwvfg/>. Consulté le: 12 juil. 2012.

ARGENTINE. Constitución Nacional. Sancionada por el congreso general constituyente el $1^{\circ}$ de mayo de 1853, reformada y concordada por la convención nacional ad hoc el 25 de 
septiembre de 1860 y con las reformas de las convenciones de 1866, 1898, 1957 y 1994. Disponible sur le site: <http://www.senado.gov.ar/web/interes/constitucion/atribjudicial.php>. Consulté le: 12 juil. 2012.

Ley Contencioso Administrativo de la Província de Buenos Aires. Ley no 12.008 de 01 de junio de 1999. Disponible sur le site: <http://www.gob.gba.gov.ar/legislacion/legislacion/l-12008.html>. Consulté le: 12 juil. 2012.

ASSOCIATION DES JUGES FÉDÉRAUX DE MINAS GERAIS - AJUFEMG (Brésil). Cartilha Novos Tribunais: uma questão de justiça. Minais Gerais: AJUFEMG, 2010.

AUTRICHE. Bundes-Verfassungsgesetz $(B-V G)$. Constitution du $1^{\circ}$ octobre 1920. Disponible sur le site: < http://www.verfassungen.de/at/ >. Consulté le: 12 juil. 2012.

BELGIQUE. Constitution Belge. Constitution de 1993. Texte coordonné le 17 février 1994. Disponible sur le site: <http://www.senate.be/doc/const_fr.html>. Consulté le: 12 juil. 2012.

Loi du 23 décembre 1946 - Loi du Conseil d'État de Belgique. Loi du 23 décembre 1946. Disponible sur le site: <http://www.juradmin.eu/fr/members/pdf/belgique.pdf>. Consulté le: 12 juil. 2012.

BRÉSIL. Código de Organização e Divisão Judiciárias do Estado do Rio de Janeiro. Actualisé le 27 avril 2011. Disponible sur le site: <http://www.tjrj.jus.br/consultas/codrj_regimento_tjrj/codjerj_novo.pdf $>$. Consulté le: 12 juil. 2012.

Conselho Nacional de Justiça (Conseil National de Justice). Justiça em números. Dados colhidos no ano-base de 2009. Disponible sur le site: <http://www.cnj.jus.br/>. Consulté le: 12 juil. 2012.

Superior Tribunal de Justiça. (Tribunal Supérieur de Justice). Regimento interno. Disponible sur le site: <http://www.dji.com.br/normas_inferiores/regimento_interno_e_sumula_stj/ristj_0008a0009 .htm\#Art.\%209\%BA>. Consulté le: 12 juil. 2012.

BREWER-CARÍAS, Allan. Bases constitucionales del derecho administrativo. In: Estudios de derecho administrativo 2005-2007. Caracas: Editorial Jurídica Venezuelana, 2007.

Principios del procedimiento administrativo en América Latina. Bogotá: Legis, 2003.

BRUNO, Cássio; BASTOS, Isabela; CASTRO, Juliana; RAMALHO, Sérgio. Que lei de acesso é essa?, reage uma servidora. $O$ Globo, 17 mai 2012. Disponible sur le site: $<$ http://clippingmp.planejamento.gov.br/cadastros/noticias/2012/5/17/que-lei-de-acesso-eessa-reage-uma-servidora>. Consulté le: 15 juin 2012.

CHILI. Codigo Organico de Tribunales. Ley no 7.421, de 15 de junio de 1943. Disponible sur le

site:

$<$ http://www.leychile.cl/Consulta/Exportar?radioExportar=Normas\&exportar_formato=pdf\&n ombrearchivo=NORMA255630\&exportar_con_notas_bcn=True\&exportar_con_notas_origin ales=True\&exportar_con_notas_al_pie=True\&hddResultadoExportar=25563.2012-0314.0.0\%23>. Consulté le: 12 juil. 2012. 
CODE de Procédure Administrative allemand. Traduction et annotations Alberto Augusto Andrade de Oliveira. Coimbra: Livraria da Universidade - DL, 1996.

COLOMBIE. Constitución Política de Colombia. Constitution Politique de Colombie, du 20 juillet $1991 . \quad$ Disponible le sur <http://www.secretariasenado.gov.co/senado/basedoc/cp/constitucion_politica_1991.html\#1>. Consulté le: 12 juil. 2012.

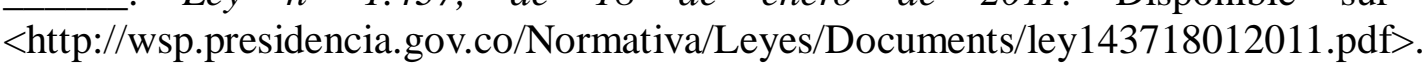
Consulté le: 12 juil. 2012.

COSTA RICA. Código Procesal Contencioso-Administrativo. Ley $n^{\circ} 8.508$, de $1^{\circ}$ de enero de 2008. Disponible sur le site: <http://www.tse.go.cr/pdf/normativa/codigoprocesalcontencioso.pdf $>$. Consulté le: 12 juil. 2012.

. Constitucion Politica de la Republica de Costa Rica de 1949. Actualizada hasta Ley $\mathrm{n}^{\circ}$ 8.365, del 15 de julio del 2003. Disponible sur le site: <http://pdba.georgetown.edu/Constitutions/Costa/costa2.html>. Consulté le: 12 juil. 2012.

. Ley Organica del Poder Judicial. Ley n ${ }^{\circ} 7.333 / 1993$, modificada por la Ley n n $^{\circ} .728$, de 15 de diciembre de 1997. Disponible sur le site: < http://www.tse.go.cr/pdf/normativa/leyorganicapoderjudicial.pdf >. Consulté le: 12 juil. 2012.

GARCÍA DE ENTERRÍA, Eduardo. La lucha contra las inmunidades del poder. 3. ed. Madri: Civitas, 1995.

; FERNÁNDEZ, Tomás-Ramón. Curso de direito administrativo. Traduction Arnaldo Setti. São Paulo: Revista dos Tribunais, 1991.

ESPAGNE. Constitución Española, de 29 de diciembre de 1978. Disponible sur le site: <http://noticias.juridicas.com/base_datos/Admin/constitucion.t4.html>. Consulté le: 12 juil. 2012.

Ley $n^{o}$ 23, de 7 de julio de 1998. Disponible sur le site: <http://noticias.juridicas.com/base_datos/Admin/123-1998.html>. Consulté le: 12 juil. 2012.

FORSTHOFF, Ernst. Tratado de derecho administrativo. Traduction Legaz Lacambra, Garrido Falla et Gómez de Ortega y Junge. Madri: Instituto de Estudios Politicos, 1958.

FRANCE. Code de Justice Administrative. Dernière modification le 20 juin 2012. Disponible sur le site: <http://www.legifrance.gouv.fr/affichCode.do;jsessionid=6CFB30A3E26674D0A68270CCB DAE2318.tpdjo10v_1?idSectionTA=LEGISCTA000006150379\&cidTexte=LEGITEXT00000 6070933\&dateTexte=20120710>. Consulté le: 12 juil. 2012.

FROMONT, Michel. Droit administratif des Etats européens. Paris: PUF, 2006.

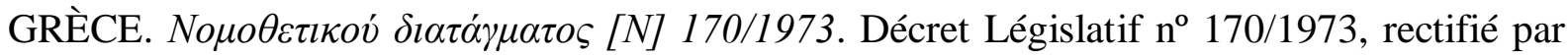
les Lois $n^{\circ} 702 / 1977$ et $n^{\circ} 1470 / 1984$ et codifié par le Décret $n^{\circ} 18 / 1989$. Disponible sur le 
site: <https://technologismiki.com/nomos/index.html?pd_18_89_77.php>. Consulté le: 12 juil. 2012.

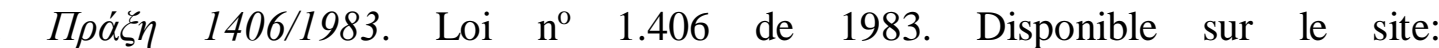
<http://www.kostasbeys.gr/articles.php?s=5\&mid=1479\&mnu=3\&id=17277>. Consulté le: 12 juil. 2012.

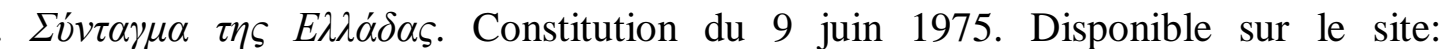

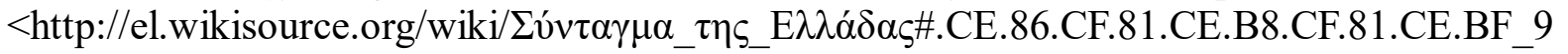
4>. Consulté le: 12 juil. 2012.

HONGRIE. Bírósági szervezet szóló 1997. Loi de L'Organisation Judiciaire de 1997. Disponible sur le site: <http://jogi-asszisztens.blog.hu/2008/07/02/a_birosagi_szervezet>. Consulté le: 12 juil. 2012.

INSTITUTO IBERO-AMERICANO DE DIREITO PROCESSUAL. (Institut IbéroAméricain de Droit Processuel) Código Modelo de Processos Administrativos - Judicial e Extrajudicial - para Ibero-América. Buenos Aires: IIDP, 2012. Disponible sur le site: < http://papers.ssrn.com/sol3/papers.cfm?abstract_id=2250852 >. Consulté le: 16 juin. 2012.

ITALIE. Costituzione della Repubblica Italiana, de 27 de dicembre de 1947. Disponible sur le site:

<http://www.senato.it/documenti/repository/relazioni/libreria/Costituzione_anastatica.pdf $>$.

Consulté le: 12 juil. 2012.

Legge 27 aprile 1982, n. 186. Loi $\mathrm{n}^{\circ}$ 186, du 27 avril 1982. Disponible sur le site: <http://www.giustizia-amministrativa.it/iper/186-1982.htm>. Consulté le: 12 juil. 2012.

MATSUURA, Lilian. Para brasileiro, Justiça é lenta, cara e parcial. Consultor Jurídico, 22 fév. 2009. Disponible sur le site: <http://www.conjur.com.br/2009-fev-22/brasileiro-poderjudiciario-lento-caro-imparcial>. Consulté le: 16 juin. 2012.

MAURER, Hartmut. Direito administrativo geral. Barueri: Manole, 2006.

MAYER, Otto. Derecho administrativo alemán. Buenos Aires: Depalma, 1982. t. I.

MELlO, Celso Antônio Bandeira de. Curso de direito administrativo. 21. ed. São Paulo: Malheiros, 2006.

MÉXIQUE. Constitucion Política de los Estados Unidos Mexicanos, de 5 de febrero de 1917. Disponible sur le site: <http://info4.juridicas.unam.mx/ijure/fed/9/95.htm?s>. Consulté le: 12 juil. 2012.

Ley Orgánica del Tribunal Federal de Justicia Fiscal y Administrativa. Dernière réforme publiée le 3 juin 2011. Disponible sur le site: <http://www.diputados.gob.mx/LeyesBiblio/pdf/LOTFJFA.pdf>. Consulté le: 12 juil. 2012.

MEYER, Hans. El procedimiento administrativo en la Republica Federal de Alemania. In: VAZQUEZ, Javier Barnés (Org.). El procedimento administrativo en el derecho comparado. Madri: Civitas, 1993. 
MIRANDA, Henrique Savonitti. Licitações e contratos administrativos. Brésilia: Escola Nacional de Administração Pública (École Nationale de l'Administration Publique), 2004. Disponible sur le site: <www.enap.gov.br/downloads/ec43ea4fUFAM-HenriqueLicita.pdf >. Consulté le: 19 avr. 2011.

MORAES, Vânila Cardoso Andre de. Demandas repetitivas decorrentes de ações ou omissões da Administração Pública: hipóteses de soluções e a necessidade de um direito processual público fundamentado na Constituição. 2011. 231 f. Mémoire (Master en Justice Administrative) - Université Fédérale Fluminense, Niterói, RJ, 2011. Disponible sur le site: < http://www2.cjf.jus.br/ojs2/index.php/mono/index >. Consulté le: 12 juil. 2012.

PAYS-BAS. Wet van 9 maart 1962, op de Raad van State. Loi du 9 mars 1962. Disponible sur le site: <http://maxius.nl/wet-op-de-raad-van-state/artikel1/>. Consulté le: 12 juil. 2012.

PERLINGEIRO, Ricardo. A impugnação judicial de atos administrativos na defesa de interesses difusos, coletivos e individuais homogêneos. In: XXVIII Congreso Colombiano De Derecho Procesal. Bogotá: Universidad Libre, p. 919-938, 2007. Disponible sur le site: <http://papers.ssrn.com/sol3/papers.cfm?abstract_id=2250854>. Consulté le: 5 juil. 2013.

O princípio da isonomia na tutela judicial individual e coletiva, e em outros meios de solução de conflitos, junto ao SUS e aos planos privados de saúde. In: NOBRE, Milton; DIAS, Ricardo (Orgs.). O Conselho Nacional de Justiça e os desafios da efetivação do direito à saúde. Belo Horizonte: Fórum, 2011. Disponible sur le site: <http://papers.ssrn.com/sol3/papers.cfm?abstract_id=2241142>. Consulté le: 5 juil. 2013.

; BLANKE, Hermann-Josef; SOMMERMANN, Karl-Peter (Coords.). Código de jurisdição administrativa: o modelo alemão. Rio de Janeiro: Renovar, 2009.

PÉROU. Constitucion Politica del Peru de 1993. Disponible sur le site: $<$ http://peru.justia.com/federales/constitucion-politica-del-peru-de-1993/titulo-iv/capituloviii/>. Consulté le: 12 juil. 2012.

\section{Disponible sur le site: <http://www.unmsm.edu.pe/ogp/ARCHIVOS/LEY\%20DEL\%20PROCEDIMIENTO\%20AD MINISTRATIVO.htm>. Consulté le: 12 juil. 2012.}

POCHARD, Marcel. La Administración Pública y la protección de los derechos fundamentales. In: CONSEJO DE ESTADO DE LA REPÚBLICA DE COLOMBIA. Seminario Franco-Colombiano sobre la Reforma a la Jurisdicción Contencioso Administrativa. Bogotá: Imprenta Nacional de Colombia, 2008.

PORTUGAL. Código de Processo nos Tribunais Administrativos. Loi no 4-A, du 19 février 2003. Disponible sur le site: <http://www.stadministrativo.pt/pdf/CodigoDeProcessoNosTribunaisAdministrativos.pdf>. Consulté le: 12 juil. 2012.

Constituição da República Portuguesa, de 2 de abril de 1976. (Constitution de la République Portugaise du 2 avril 1976). Revision VII de 2005. Disponible sur le site: 
<http://www.parlamento.pt/Legislacao/Paginas/ConstituicaoRepublicaPortuguesa.aspx >. Consulté le: 12 juil. 2012.

Estatuto dos Tribunais Administrativos e Fiscais. Loi no 13, du 31 janvier 2002. Disponible sur le site: <http://portolegal.jurispro.net/ETAF.htm>. Consulté le: 12 juil. 2012.

ROCHA, Carmen Lúcia Antunes. Princípios constitucionais do processo administrativo no Direito brasileiro. Revista de Informação Legislativa, Brésilia: Sénat Fédéral, anné 34, n. 136, p. 5-28, oct./déc. 1997.

SADEK, Maria Teresa. Judiciário e arena pública: um olhar a partir da ciência política. In: GRINOVER, Ada Pellegrini; WATANABE, Kazuo (Org.). O controle jurisdicional de políticas públicas. 1. ed. Rio de Janeiro: Forense, 2011.

SCHMIDT-AßMANN, E. Sobre el objeto del procedimiento administrativo em la dogmática administrativa alemana. In: VAZQUEZ, Javier Barnés (Org.). El procedimento administrativo en el derecho comparado. Madri: Civitas, 1993.

SIRINELLI, Jean. Les transformations du droit administratif par le droit de l'Union Européenne. Paris: LGDJ, 2011.

SUÈDE. Författning 1974. Constitution de 1974. Approuvée le $1^{\circ}$ janvier 1975. Disponible sur le site: <http://www.servat.unibe.ch/icl/sw00000_.html>. Consulté le: 12 juil. 2012.

SUISSE. Bundesgerichtsgesetz, BGG. Loi du 17 juin 2005. Disponible sur le site: <http://www.admin.ch/ch/d/sr/173_110/index.html>. Consulté le: 12 juil. 2012.

Bundesgesetz über das Verwaltungsverfahren. Loi du 20 décembre 1968. Disponible sur le site: 〈http://www.admin.ch/ch/d/sr/1/172.021.de.pdf>. Consulté le: 12 juil. 2012.

Verfassung der Schweiz. Constitution approuvée par le référendum du 12 mars 2000. Disponible sur le site: <http://www.servat.unibe.ch/icl/sz00000_.html>. Consulté le: 12 juil. 2012.

UNIVERSIDADE FEDERAL FLUMINENSE. (Université Fédérale Fluminense). Núcleo de Ciências do Poder Judiciário (Centre des Sciences du Pouvoir Judiciaire). Projeto Acadêmico do Programa de Pós-Graduação Justiça Administrativa (Projet Académique du Programme de Post-grade en Justice Administrative)- PPGJA-UFF. Niterói, 2008.

VENEZUELA. Constitución de la República Bolivariana de Venezuela de 1999. Disponible sur le site: <http://www.filosofia.org/cod/c1999ven.htm>. Consulté le: 12 juil. 2012.

WOLFF, Hans J.; BACHOF, Otto; STOBER, Rolf. Direito administrativo. Traduction Antônio F. de Sousa. Lisboa: Fundação Calouste Gulbenkian, 2006.

ZAFFARONI, Eugenio Raúl. Poder Judiciário. São Paulo: Revista dos Tribunais, 1995.

ZILLER, Jacques. Administrations comparées. Les systèmes politico-administratifs de l'Europe des Douze. Paris: Montchrestien, 1993. 


\section{PRÉCÉDENTS JUDICIAIRES}

BRÉSIL. Supremo Tribunal Federal (Cour Suprême Fédérale). AI 59.7182. $2^{\mathrm{a}}$ Classe. Rapporteur min. Cezar Peluso. Brésilia, DF. Publié le: 6 nov. 2006. Disponible sur le site: $<$ http://redir.stf.jus.br/paginadorpub/paginador.jsp?docTP=AC\&docID=390282>. Consulté le: 12 juil. 2012.

Supremo Tribunal Federal. (Cour Suprême Fédérale). AI 64.1911, AgR. $1^{\text {a }}$ Classe. Rapporteur min. Cármen Lúcia. Brésilia, DF. Publié le: $1^{\circ}$ oct. 2009. Disponible sur le site: $<$ http://redir.stf.jus.br/paginadorpub/paginador.jsp?docTP=AC\&docID=603416>. Consulté le: 12 juil. 2012.

Supremo Tribunal Federal. (Cour Suprême Fédérale). AI 685-866-AgR. Rapporteur min. Ricardo Lewandowski. Brésilia, DF. Publié le: 22 mai 2009. Disponible sur le site: $<$ http://redir.stf.jus.br/paginadorpub/paginador.jsp?docTP=AC\&docID=593889>. Consulté le: 12 juil. 2012.

Supremo Tribunal Federal. (Cour Suprême Fédérale). MS 25.787-3/DF. Rapporteur min. Gilmar Mendes. Brésilia, DF. Publié le: 14 sept. 2007. Disponible sur le site: $<$ http://redir.stf.jus.br/paginadorpub/paginador.jsp?docTP=AC\&docID=486706>. Consulté le: 12 juil. 2012.

Supremo Tribunal Federal. (Cour Suprême Fédérale). RE 116.683. Rapporteur min. Celso de Mello. Brésilia, DF. Publié le: 13 mar. 1993. Disponible sur le site: $<$ http://redir.stf.jus.br/paginadorpub/paginador.jsp?docTP=AC\&docID=206504>. Consulté le: 12 juil. 2012.

Supremo Tribunal Federal. (Cour Suprême Fédérale). SL 47 AgR. Pleno. Rapporteur min. Gilmar Mendes. Brésilia, DF. Publié le: 30 avr. 2010. Disponible sur le site: $<$ http://redir.stf.jus.br/paginadorpub/paginador.jsp?docTP=AC\&docID=610254>. Consulté le: 12 juil. 2012.

Supremo Tribunal Federal. (Cour Suprême Fédérale). Súmula Vinculante $n^{o} 3$. Session Plénière, 30 mai 2007. Brésilia, DF. Publié le: 6 juin 2007. Disponible sur le site: <http://www.dji.com.br/normas_inferiores/regimento_interno_e_sumula_stf/0003vinculante.h tm>. Consulté le: 12 juil. 2012.

Tribunal de Contas da União. (Cour des Comptes de l'Union). Regimento interno. Approuvé par la Résolution Administrative no 246, du 30 novembre 2011. Disponible sur le site:

<http://portal2.tcu.gov.br/portal/page/portal/TCU/normativos/sobre_normativos/regimento.pd f>. Consulté le: 12 juil. 2012.

. Tribunal de Contas da União. (Cour des Comptes de l'Union). Acórdão 2.553/2009. Session Plénière. Rapporteur min. José Jorge. Brésilia, DF. Publié le: 4 nov. 2009. Disponible sur le site: <https://contas.tcu.gov.br/juris/SvlHighLight?key=ACORDAO-LEGADO80678\&texto=32353533\&sort=DTRELEVANCIA\&ordem=DESC\&bases=ACORDAOLEGADO;DECISAO-LEGADO;RELACAO-LEGADO;ACORDAO-RELACAOLEGADO;\&highlight=32353533\&posicaoDocumento=0>. Consulté le: 12 juil. 2012. 
Tribunal Regional Federal da $2^{\mathrm{a}}$ Região. (Tribunal Régional Fédéral de la $2^{\circ}$ Région). $A G$ 201102010109190. $5^{\text {a }}$ Classe. Rapporteur juge Ricardo Perlingeiro. Publié le fév. 2012. Disponible sur le site: <www.trf2.jus.br>. Consulté le: 12 juil. 2012.

Tribunal Regional Federal da $2^{\mathrm{a}}$ Região. (Tribunal Régional Fédéral de la $2^{\circ}$ Région). Regimento interno. Diário da Justiça da União, du 29 janvier 2009. Actualisé jusqu'à l'Altération au Règlement $\mathrm{n}^{\mathrm{o}}$ 26, du 14 mai 2012. Disponible sur le site: <http://www10.trf2.jus.br/ai/regimento-interno/ >. Consulté le: 12 juil. 2012.

CORTE INTERAMERICANA DE DIREITOS HUMANOS. Caso Radilla Pacheco vs. México. Excepciones Preliminares, Fondo, Reparaciones y Costas. Sentencia de 23 de Noviembre de 2009. Serie C No. 209. Disponible sur le site: < http://www.ordenjuridico.gob.mx/JurInt/STCIDHM4.pdf >. Consulté le: 12 juil. 2012.

Submetido em: 20/02/2019

Aceito em: 27/03/2019 